\title{
Simulation and analysis of solute transport in 2D fracture/pipe networks: The SOLFRAC program
}

Jacques Bodin $^{1,2, *}$, Gilles Porel ${ }^{1,2}$, Fred Delay ${ }^{1,2}$, Fabrice Ubertosi ${ }^{1,2}$, Stéphane Bernard ${ }^{1,2}$, and Jean-Raynald de Dreuzy 3,4

${ }^{1}$ Université de Poitiers, FRE 3114 HydrASA, 40 av. Recteur Pineau, 86022 Poitiers Cedex, France

${ }^{2}$ CNRS/INSU, FRE 3114 HydrASA, 40 av. Recteur Pineau, 86022 Poitiers Cedex, France

${ }^{3}$ Université de Rennes 1, UMR CNRS 4661, Campus de Beaulieu, 35042 Rennes Cedex, France

${ }^{4}$ CNRS/INSU, UMR CNRS 4661, Campus de Beaulieu, 35042 Rennes Cedex, France

*Corresponding author. E-mail: jacques.bodin@univ-poitiers.fr / Telephone: (+33)549454106 / Fax: (+33)549454241.

\section{Abstract}

The Time Domain Random Walk (TDRW) method has been recently developed by Delay and Bodin (2001) and Bodin et al. (2003c) for simulating solute transport in discrete fracture networks. It is assumed that the fracture network can reasonably be represented by a network of interconnected one-dimensional pipes (i.e. flow channels). Processes accounted for are: (1) advection and hydrodynamic dispersion in the channels, (2) matrix diffusion, (3) diffusion into stagnant zones within the fracture planes, (4) sorption reactions onto the fracture walls and in the matrix, (5) linear decay, and (6) mass sharing at fracture intersections. The TDRW method is handy and very efficient in terms of computation costs since it allows for the onestep calculation of the particle residence time in each bond of the network. This method has been programmed in $\mathrm{C}++$, and efforts have been made to develop an efficient and user- 
friendly software, called SOLFRAC. This program is freely downloadable at the URL http://labo.univ-poitiers.fr/hydrasa/intranet/telechargement.htm. It calculates solute transport into 2D pipe networks, while considering different types of injections and different concepts of local dispersion within each flow channel. Post-simulation analyses are also available, such as the mean velocity or the macroscopic dispersion at the scale of the entire network. The program may be used to evaluate how a given transport mechanism influences the macroscopic transport behaviour of fracture networks. It may also be used, as is the case, e.g., with analytical solutions, to interpret laboratory or field tracer test experiments performed in single fractures.

Key words: numerical modelling; solute transport; fractured rocks

\section{Introduction}

In many geologic formations, fractures represent preferential pathways along which a dissolved contaminant can migrate rapidly. The understanding and quantification of solute transport in fractured rocks is therefore of considerable practical importance in terms of aquifer preservation. There are three main approaches to simulating solute transport in fractured rocks: discrete network simulations (Andersson and Thunvik 1986; Cacas et al. 1990a; Dverstorp et al. 1992; Dershowitz et al. 1999; Huseby et al. 2001), continuum approaches based on either equivalent-porous-medium (EPM) assumption (Long et al. 1982; Berkowitz et al. 1988; McKay et al. 1997; Gburek and Folmar 1999; Jackson et al. 2000) or dual/triple-continuum approximations (Bibby 1981; Huyakorn et al. 1983a, 1983b; Gerke and van Genuchten 1996; Leo and Booker 1996; Kischinhevsky and Paes-Leme 1997; Arnold et al. 2000; Lichtner 2000; Hassan and Mohamed 2003; Wu et al. 2004), and hybrid models that combine elements of both discrete network simulations and continuum approaches (Schwartz 
and Smith 1988; Grandi and Ferreri 1994; National Research Council 1996; Tsang et al. 1996; Stafford et al. 1998; Lee et al. 2001; Ohman et al. 2005).

As emphasized by Long et al. (1982) and Berkowitz et al. (1988), the validity of continuum approaches for fracture networks depends on several parameters, the most important being the existence of a Representative Elementary Volume (REV), i.e. a volume above which the flow and transport properties of the fractured rock can be considered as statistically homogeneous. This assumption, however, does not hold for fractured rocks in general. Several authors have shown that most natural fracture networks exhibit fractal or scale-dependent properties (Neuman 1990; Velde et al. 1991; Vignes-Adler et al. 1991; Guimera et al. 1995; Cowie et al. 1996; Bour and Davy 1997; Bodin and Razack 1999). In that case, the homogenization scale of the network is difficult, or perhaps even impossible, to identify.

In the discrete framework, individual fractures are explicitly incorporated into the spatial domain. For 2D analyses, the fractures are represented by 1D-pipe elements (Schwartz et al. 1983; Smith and Schwartz 1984; Robinson and Gale 1990; de Dreuzy et al. 2001a, 2001b, 2002; de Dreuzy et al. 2004). For 3D problems, the fractures are represented by 2D-planar elements, which can be either disk-shaped (Andersson and Dverstorp 1987; Billaux et al. 1989), elliptical (de Dreuzy et al. 2000), or polygonal (Huseby et al. 2001). A good review on the art of simulating realistic 3D fracture networks can be found in National Research Council (1996). Once a 3D fracture network has been generated, the flow and transport calculations are performed on either 2D numerical grids constructed in each fracture plane (Nordqvist et al. 1992; Therrien and Sudicky 1996; Huseby et al. 2001; Reichenberger et al. 2005), or in a network of interconnected 1D pipes derived from the fracture network (Cacas et al. 1990a; Cacas et al. 1990b; Dverstorp et al. 1992; Moreno and Neretnieks 1993; Dershowitz and 
Fidelibus 1999; Jourde et al. 2002). These two alternatives are illustrated in Fig. 1. Discretising fractures into regular or irregular grids is the more rigorous approach since aperture variations in each fracture plane are accounted for. Unfortunately, this is also very computationally demanding since flow and transport equations have to be solved for each grid element. Today's computer capabilities are far from sufficient to enable field-scale analyses using this method since a number of fractures of $10^{5}-10^{7}$ is often required to correctly depict the medium.

Modelling flow and transport in pipe networks is more computationally efficient as two- or three-dimensional problems are reduced to a series of one-dimensional ones. A physical justification of this conceptualization is that fluid flow through rock fractures is often concentrated along preferential pathways, corresponding to the paths with the lowest hydraulic resistance (Tsang and Neretnieks 1998; Bodin et al. 2003a). Of course, the use of the pipe network approach needs to address the problem of parameterisation. The number, location, and aperture distribution of flow channels have to be specified. For a real case problem, it is not clear whether such parameters may be accessed by current field investigation methods. Note that a similar problem exists with the gridding approach, because in-situ characterization of aperture distributions within fractures planes is virtually impossible. Also note that instead of considering gridded fracture models and pipe network models as rivals, these two approaches may be viewed as complementary. One could compute flow in a few gridded fractures in order to get statistics about the geometry of preferential pathways, and then simulate channel networks on a greater scale.

The aim of this paper is to present a program called SOLFRAC, which enables to simulate and analyze solute transport in complex fracture networks using a pipe network 
approximation. It is freely downloadable at the URL http://labo.univpoitiers.fr/hydrasa/intranet/telechargement.htm. This software has been developed for academic research purposes and therefore focuses on two-dimensional fracture networks only, i.e. pipe networks interconnected in 2D space. Note that all the modelling concepts and numerical methods presented in this work could be easily adapted for simulating solute transport in pipe networks interconnected in 3D space (i.e. 3D fracture networks). In that case, most efforts should be put on the network simulator and not on the transport algorithms that are described in the present paper.

\section{Input data files}

The 2D fracture networks handled by the program are delimited by square domains of $L \times L$ in size. Fluid flow is established between the top and bottom faces by assigning constant values of hydraulic head to all fractures intersecting those faces. Impermeable boundaries are assigned to the remaining two faces. Each fracture is modelled as a rectangular pipe with constant aperture and width, the latter parameters possibly differing from one fracture to another. In such networks, the computation of hydraulic head at each node is performed by assuming that the flow in each bond obeys Darcy's law and by applying the principle of conservation of fluid mass at each node (i.e. Kirchhoff's law). This leads to a linear system of algebraic equations, which can be solved by either direct or iterative methods, see e.g. Gill et al. (1991).

The input data files required by the program are in text format. These files include the information describing the geometry of the fracture networks, the hydraulic conductivity of each fracture, and the hydraulic head values at each node. The file format used is very similar to that of the output files of the code developed by de Dreuzy et al. (2001a, 2001b, 2002, 
2004) for analyzing the hydraulic properties of $2 \mathrm{D}$ random fracture networks following a power law length distribution. Further details about the structure of input files are given at the URL http://labo.univ-poitiers.fr/hydrasa/intranet/telechargement.htm. A program enabling to generate input files for SOLFRAC is also freely downloadable at this URL. This program, called MODFRAC, has been developed by Bernard (2002) and Ubertosi (2003). It generates 2D fracture networks according to a wide range of statistical distribution functions for fracture density, orientation, aperture, and length. The hydraulic head value at each node can be computed by either direct methods (Cholesky or Gauss Jordan) or iterative ones (conjugate gradient or Gauss-Seidel).

\section{Transport simulations}

\section{Transport equations}

The transport simulations handled by the program are limited to scenarios for single-phase, isothermal flow conditions in which the solute concentration is diluted enough to neglect density effects. Hydraulic properties are assumed to remain constant in time, i.e. it is assumed that coupling between fluid pressure and rock stress is negligible and that chemical reactions (such as precipitation and/or dissolution) that could modify fracture openings do not occur. The model accounts for the following transport processes: advection and hydrodynamic dispersion in the fractures, matrix diffusion, diffusion into stagnant zones within the fracture planes, sorption reactions onto the fracture walls and in the matrix, linear decay, and mass sharing at fracture intersections. Both the rock matrix and the stagnant zones are considered as immobile pore spaces in which the movement of tracers is due to molecular diffusion only (advection is neglected). A sketch illustrating a fracture-matrix system with stagnant zones in the fracture plane is given in Fig. 2. In the mathematical development of the transport equations, we make the following major assumptions: (1) the fluid velocity is constant 
between two successive fracture intersections, (2) transverse diffusion and dispersion within each flow channel ensure complete mixing across its width, (3) dispersion in each flow channel is assumed to be Fickian or based on an expression making its first spatial derivative easy to approximate, (4) sorption reactions onto the fracture walls and in the matrix obey linear instantaneous equilibriums, (5) diffusion into stagnant zones within the fracture plane is perpendicular to the flow direction, (6) diffusion in the matrix is perpendicular to the fracture plane (diffusive fluxes parallel to the fracture plane are neglected), (7) the extent of solute diffusion within the rock matrix is small enough so that diffusion from adjacent fracture elements does not interact, (8) diffusion in the fracture plane and diffusion in the surrounding rock matrix are two independent processes that do not interact (i. e. diffusive fluxes between the stagnant zones and the rock matrix are neglected). With the above assumptions, the solute transport in each branch of the network (i.e. in each flowing bond between two nodes) is described by three coupled one-dimensional equations: one for the flow channel, one for the stagnant zones, and one for the porous matrix attached to the bond. The coupling is provided by the continuity of concentrations along the interface between the flow channel and the stagnant zones, and between the flow channel and the rock matrix. The transport equation in the fracture is written as:

$$
\frac{\partial c_{f}}{\partial t}+\lambda c_{f}=-\frac{u_{f}}{R_{f}} \frac{\partial c_{f}}{\partial x}+\frac{1}{R_{f}} \frac{\partial}{\partial x}\left(D_{f} \frac{\partial c_{f}}{\partial x}\right)+\left.\frac{D_{m}}{a R_{f}} \frac{\partial c_{n f}}{\partial y}\right|_{y=a}+\left.\frac{D_{e}}{b R_{f}} \frac{\partial c_{m}}{\partial z}\right|_{z=b}
$$

where $c_{f}\left[M \cdot L^{-3}\right]$ is the solute concentration in the flow channel; $\lambda\left[T^{-1}\right]$ is the decay constant of the solute; $t[T]$ is the time variable; $x[L]$ is the space coordinate along the flow channel; $u_{f}$ $\left[L \cdot T^{-1}\right]$ is the fluid velocity in the flow channel; $D_{f}\left[L^{2} \cdot T^{-1}\right]$ is the hydrodynamic dispersion coefficient in the flow channel; $D_{m}\left[L^{2} \cdot T^{-1}\right]$ is the molecular-diffusion coefficient of the solute; $a[L]$ is the half-width of the flow channel; $c_{n f}\left[M \cdot L^{-3}\right]$ is the solute concentration in the non-flowing part of the fracture plane; $y[L]$ is the space coordinate in the fracture plane, 
perpendicular to the flow channel axis; $D_{e}\left[L^{2} \cdot T^{-1}\right]$ is the effective-diffusion coefficient of the solute in the matrix; $b[L]$ is the half-aperture of the fracture; $c_{m}\left[M \cdot L^{-3}\right]$ is the solute concentration in the matrix; $z[L]$ is the space coordinate in the matrix block, normal to the fracture plane; and $R_{f}[-]$ is a retardation factor accounting for the sorption of the solute onto the fracture walls. $R_{f}$ is defined as:

$$
R_{f}=1+\frac{K_{f}}{b}
$$

where $K_{f}[L]$ is the surface-sorption coefficient of the solute onto the fracture walls. The transport equation in the stagnant zones is written as:

$$
\frac{\partial c_{f^{\prime}}}{\partial t}+\lambda c_{f^{\prime}}=\frac{D_{m}}{R_{f}} \frac{\partial^{2} c_{n f}}{\partial y^{2}}
$$

The transport equation in the matrix is written as:

$$
\frac{\partial c_{m}}{\partial t}+\lambda c_{m}=D_{a} \frac{\partial^{2} c_{m}}{\partial z^{2}}
$$

where $D_{a}\left[L^{2} \cdot T^{-1}\right]$ is the apparent-diffusion coefficient of the solute in the matrix, expressed as a function of $\theta_{m}[-]$ the matrix porosity, $\rho_{m}\left[M \cdot L^{-3}\right]$ the bulk density of the matrix, and $K_{m}$ $\left[L^{3} \cdot M^{-1}\right]$ the volumetric-sorption coefficient of the solute in the matrix:

$$
D_{a}=\frac{D_{e}}{\theta_{m}+\rho_{m} K_{m}}
$$

Transport simulations are performed using the Time Domain Random Walk (TDRW) method, recently developed by Delay and Bodin (2001) and Bodin et al. (2003c), from the original work by Banton et al. (1997). The TDRW method is a Lagrangian method developed in the time domain. It allows for the one-step calculation of the particle residence time in each bond of the network and is thus very efficient in terms of computation costs, while preserving accuracy. The fundamentals of this method are summarized below. 


\section{The TDRW method}

For the sake of simplicity, the role of stagnant zones within fracture planes is neglected in this section and will be addressed later. The time needed for a solute particle to move between two fracture intersections can then be separated in two residence times: (1) residence time of the particle in the flow channel and (2) residence time of the particle in the rock matrix adjacent to the flow channel. The TDRW method allows solving these two residence times separately. As a first step, the residence time of a particle in a bond is calculated assuming that the rock matrix is totally impervious, i.e. there is no matrix diffusion. In the Lagrangian framework, considering the change of variable:

$$
\frac{\partial c_{f}}{\partial t}=\frac{\partial c_{f}}{\partial x} \frac{\partial x}{\partial t}=\frac{\partial c_{f}}{\partial x} \frac{u_{f}}{R_{f}}
$$

the transport equation in a bond can be rewritten as:

$$
\frac{\partial c_{f}}{\partial x}+\lambda c_{f} \frac{R_{f}}{u_{f}}=-\frac{R_{f}}{u_{f}^{2}} \frac{\partial}{\partial t}\left[\left(u_{f}+\frac{\partial D_{f}}{\partial x}\right) c_{f}\right]+\frac{R_{f}^{2}}{u_{f}^{3}} \frac{\partial^{2}}{\partial t^{2}}\left(D_{f} c_{f}\right)
$$

Note that expression (7) is an advection-dispersion equation written with the Fokker-Plank formalism. From the equivalence between this expression and the random-walk approach to transport, Bodin et al. (2003c) showed that the mean and variance of particle travel times could be easily identified. For an elementary displacement of length dx, these terms are written, respectively, as:

$$
\begin{gathered}
\mu_{t}(d x)=\frac{R_{f}}{u_{f}^{2}}\left(u_{f}+\frac{\partial D_{f}}{\partial x}\right) d x \\
\sigma_{t}^{2}(d x)=R_{f}^{2} \frac{2 D_{f}}{u_{f}^{3}} d x
\end{gathered}
$$

Because the particle motion along a bond of length $L$ can be considered as a series of independent jumps, the means and variances are additive (Rasmuson 1985; Bodin et al. 
2003c). Thus, the mean and variance of the particle travel time distribution for a displacement of length $L$ are written as:

$$
\begin{gathered}
\mu_{t}=\frac{R_{f}}{u_{f}^{2}} \int_{0}^{L}\left(u_{f}+\frac{\partial D_{f}}{\partial x}\right) d x=\frac{R_{f}}{u_{f}^{2}}\left(u_{f} L+\int_{0}^{L} \frac{\partial D_{f}}{\partial x} d x\right) \\
\sigma_{t}^{2}=\frac{2 R_{f}^{2}}{u_{f}^{3}} \int_{0}^{L} D_{f} d x
\end{gathered}
$$

For Péclet numbers $P e=u_{f} L / D_{f}$ larger than 10 , it can be shown that the travel time distribution is lognormal (Bodin et al. 2003c). Therefore, the stochastic calculation of travel times over a distance $L$ is given by:

$$
\begin{gathered}
\ln \left(\Delta t_{f}\right)=\mu_{\ln }+Z_{N} \sigma_{\ln } \\
\mu_{\ln }=\ln \left(\mu_{t} / \sqrt{1+\sigma_{t}^{2} / \mu_{t}^{2}}\right) \\
\sigma_{\ln }^{2}=\ln \left(1+\sigma_{t}^{2} / \mu_{t}^{2}\right)
\end{gathered}
$$

where $\mu_{t}[T]$ and $\sigma_{t}^{2}\left[T^{2}\right]$ are the mean and variance in (10) and (11), $\Delta t_{f}[T]$ the particle travel time for a travel distance $L, Z_{N}$ a random number drawn from a normal deviate, and $\mu_{\mathrm{ln}}[T]$ and $\sigma_{\mathrm{nn}}{ }^{2}\left[T^{2}\right]$ the mean and variance of the log transform. Note that the TDRW method enables the scale-dependent dispersion coefficient to be dealt with, provided that the spatial derivative in (10) is calculable. If indexes $n$ and $n+1$ refer to the upstream and downstream nodes of a bond of length $L$, the particle travel time in this bond can be written as:

$$
t_{n+1}-t_{n}=\Delta t_{f}=\exp \left(\mu_{\mathrm{ln}}+Z_{N} \sigma_{\mathrm{ln}}\right)
$$

In fracture networks, Péclet numbers can be locally less than 10 in very short bonds or in bonds with very low flow velocities. The assumption of a lognormal travel time distribution in these bonds can be flawed, and yield inaccurate results. Bodin et al. (2003c) propose an empirical correction of expression (13) to preserve accuracy of the TDRW method for $P e<$ 
10. This correction consists in multiplying expression (13) by a factor $\beta=1-1 /(33 P e)$, which leads to:

$$
\mu_{\mathrm{ln}}^{\prime}=\beta \mu_{\mathrm{ln}}=\left(1-\frac{1}{33 P e}\right) \ln \left(\frac{\mu_{t}}{\sqrt{1+\sigma_{t}^{2} / \mu_{t}^{2}}}\right)
$$

Once the residence time of the particle in a bond has been determined, the next step is to calculate the time spent by diffusion and sorption in the matrix block attached to the bond. Initial work by Delay and Bodin (2001) only applied to non-reactive solutes. The TDRW method is here re-developed to handle matrix diffusion and sorption in the matrix. A set of analytical solutions for the transport problem described by Eq. (1-5) is provided by Tang et al. (1981) for a continuous injection of constant concentration $c_{0}$ at the inlet of the fracture. In the case of both non-decaying solute and negligible dispersion in the fracture (i.e. $\lambda=0$ and $D_{f}=$ 0 ), the concentration at the outlet of a fracture of length $L$ is written as:

$$
\begin{gathered}
c_{f}=0 \text { for } 0 \leq t<t_{0} \\
c_{f}=c_{0} \operatorname{erfc}\left(\frac{\Omega t_{0}}{R_{f} \sqrt{t-t_{0}}}\right) \text { for } t \geq t_{0}
\end{gathered}
$$

where

$$
\begin{gathered}
t_{0}=R_{f} \frac{L}{u_{f}} \\
\Omega=\frac{\sqrt{\left(\theta_{m}+\rho_{m} K_{m}\right) D_{e}}}{2 b}
\end{gathered}
$$

Note that $t_{0}[\mathrm{~T}]$ is the particle residence time in the fracture, for pure advection delayed by sorption reactions onto the fracture walls. Since expressions (17) and (18) are the answer to a continuous injection, they have the significance of a cumulative probability density function for residence times by advection and matrix diffusion in a bond of length $L$. This distribution is written as: 


$$
\begin{gathered}
F_{a d}=0 \text { for } 0 \leq t<t_{0} \\
F_{a d}=\operatorname{erfc}\left(\frac{\Omega t_{0}}{R_{f} \sqrt{t-t_{0}}}\right) \text { for } t \geq t_{0}
\end{gathered}
$$

Applying the so-called rejection method (Yamashita and Kimura 1990; Moreno and Neretnieks 1993; Delay and Bodin 2001), one gets a stochastic expression of the particle residence time $\Delta t_{m}$ in the matrix:

$$
\Delta t_{m}=t-t_{0}=\left(\frac{\Omega t_{0}}{R_{f} \operatorname{erfc}^{-1}\left(U_{01}\right)}\right)^{2}
$$

where $U_{01}$ is a random number drawn from a uniform distribution between 0 and 1 . However, because Eq. (18) has been developed under the assumption of negligible dispersion in the fracture, the diffusion time $\Delta t_{m}$ cannot be merely added to the advection-dispersion time $\Delta t_{f}$ (15). Delay and Bodin (2001) have shown that the mean and variance of the travel time distribution in the bond should be modified to account for the interaction between advectiondispersion and matrix diffusion. The modification is performed as follows:

$$
\begin{gathered}
\mu_{t}^{*}=\frac{R_{f}}{u_{f}^{* 2}}\left(u_{f}^{*} L+\int_{0}^{L} \frac{\partial D_{f}^{*}}{\partial x} d x\right) \\
\sigma_{t}^{2^{*}}=2 \frac{R_{f}^{2}}{u_{f}^{3}} \int_{0}^{L} D_{f}^{*} d x
\end{gathered}
$$

where $\mu_{t}^{*}[T]$ and $\sigma_{t}^{2^{*}}\left[T^{2}\right]$ are respectively the corrected mean and variance of the advectiondispersion travel time, based on an apparent fluid-velocity $u_{f}^{*}$ and an apparent dispersion coefficient $D_{f}^{*}$ defined as:

$$
u_{f}^{*}=R_{\text {diff }} u_{f}
$$

$$
D_{f}^{*}=f\left(u_{f}^{*}\right) \text { if dispersion is modelled as being proportional to fluid velocity }
$$

(e.g. $D_{f}^{*}=\alpha u_{f}^{*}$ with $\alpha[L]$ a dispersivity constant) 


$$
D_{f}^{*}=D_{f} \text { otherwise }
$$

The coefficient $R_{\text {diff }}$ is a retardation factor that expresses the delay stemming from matrix diffusion as compared to pure advection. It can be viewed as the ratio $t_{a d} / t_{0}, t_{a d}$ being a characteristic time of advection-diffusion. Delay and Bodin (2001) propose to calculate $t_{a d}$ as follows:

$$
t_{a d}=\frac{\int_{t_{0}}^{t_{0}+B} \tau f_{a d}(\tau) d \tau}{\int_{t_{0}}^{t_{0}+B} f_{a d}(\tau) d \tau}
$$

where $t_{0}$ is defined by (19), $B[T]$ is an integration boundary, and $f_{a d}$ is the (non-cumulative) probability density function of residence times by advection-diffusion in a bond-matrix system, which can be derived from (22):

$$
f_{a d}(t)=\frac{d\left(F_{a d}\right)}{d t}=\frac{\Omega t_{0}}{R_{f} \sqrt{\pi}\left(t-t_{0}\right)^{3 / 2}} \exp \left(-\frac{\Omega^{2} t_{0}^{2}}{R_{f}^{2}\left(t-t_{0}\right)}\right)
$$

By experience, the best results are given for $B=\sigma_{t} / 2$ with $\sigma_{t}$ defined by (11). Introducing (30) into (29) and using $B=\sigma_{t} / 2$ yield the following expression for the coefficient $R_{\text {diff: }}$ :

$$
R_{\text {diff }}=1+\frac{\Omega \sqrt{2 \sigma_{t}}}{R_{f}}\left(\frac{\exp \left(-\xi^{2}\right)}{\sqrt{\pi} \operatorname{erfc}(\xi)}-\xi\right)
$$

where

$$
\xi=\frac{\Omega t_{0}}{R_{f}} \sqrt{\frac{2}{\sigma_{t}}}=\frac{\Omega L}{u_{f}} \sqrt{\frac{2}{\sigma_{t}}}
$$

One can easily check that $R_{\text {diff }}$ tends to 1 when $\xi$ tends to 0 (i.e. for negligible matrix diffusion, the advection velocity in the bond remains obviously unchanged). In summary, the total residence time of a particle in a bond-matrix system undergoing an advective-dispersive motion in the fracture, coupled to both sorption onto the fracture walls and diffusion-sorption into the matrix, can be calculated as follows: 


$$
\Delta t_{f m}=\exp \left(\mu_{\mathrm{ln}}^{\prime}+Z_{N} \sigma_{\mathrm{ln}}\right)+\left(\frac{\Omega t_{0}}{R_{f} \operatorname{erfc}^{-1}\left(U_{01}\right)}\right)^{2}
$$

where expressions (24) and (25) have to be used in place of expressions (10) and (11) in the calculus of $\mu_{\mathrm{ln}}{ }^{\prime}(16)$ and $\sigma_{\ln }{ }^{2}(14)$. If the solute undergoes linear decay, the solute mass associated with each particle is decreased at each node according to:

$$
m p_{n+1}=m p_{n} \exp \left[-\lambda \Delta t_{f m}\right]
$$

where $m p_{n}$ and $m p_{n+1}[M]$ represent the mass of the particle at nodes $n$ and $n+1$, respectively.

\section{Solute diffusion in stagnant zones}

In the preceding section, the rock matrix was considered to be the only part of the fractured system where the solute motion is purely diffusive. However, it is well known that fluid flow in natural fractures is often highly channelled, i.e. flow occurs in a relative small portion of the fracture plane (Tsang and Neretnieks 1998; Bodin et al. 2003a). The stagnant zones in the fracture plane therefore act as an additional "non-flowing" pore space available for solute diffusion. It is assumed that (1) diffusion in the fracture plane and diffusion in the surrounding rock matrix are two independent processes, and (2) diffusion in the stagnant zones is not influenced by the finite width of the fracture plane (unlimited diffusion). Using these assumptions, the transport problem described by equations (1)-(5) can be simulated as described in the previous section, while adding a residence time $\Delta t_{f^{\prime}}$ of the particle in stagnant zones to the time $\Delta t_{f m}$ (expression. 33). By analogy with the term $\Delta t_{m}$ for matrix diffusion, the expression of $\Delta t_{f}$, can be written as:

$$
\Delta t_{f^{\prime}}=\left(\frac{\Omega^{\prime} t_{0}}{R_{f} \operatorname{erfc}^{-1}\left(U_{01}^{\prime}\right)}\right)^{2}
$$

where 


$$
\Omega^{\prime}=\frac{\sqrt{R_{f} D_{m}}}{2 a}
$$

Theoretically, for the same reasons as those evoked in the previous section, the diffusion time $\Delta t_{f^{\prime}}$ cannot be merely added to the time $\Delta t_{f m}$. The mean and variance of the travel time distribution in the bond should be modified in order to account for the interaction between advection-dispersion in the flow channel and diffusion into the stagnant zones. However, the coupling error is expected to be negligible because the exchange surface between the flow channel and the stagnant zones is much more limited than the contact area with the matrix blocks. The complete expression for simulating advective-dispersive transport in a 1D-flow channel, coupled to both diffusion and sorption in adjacent rock matrix and stagnant zones in the fracture plane, can thus be written as:

$$
\Delta t_{f f^{\prime} m}=\exp \left(\mu_{\mathrm{ln}}^{\prime}+Z_{N} \sigma_{\mathrm{ln}}\right)+\left[\frac{t_{0}}{R_{f}}\left(\frac{\Omega}{\operatorname{erfc}^{-1}\left(U_{01}\right)}+\frac{\Omega^{\prime}}{\operatorname{erfc}^{-1}\left(U_{01}^{\prime}\right)}\right)\right]^{2}
$$

Note that the above developments could be generalized to any number of independent diffusion compartments.

\section{Dispersion models}

Solute dispersion in a fracture stems from the combined effects of molecular diffusion and heterogeneity of the fluid velocity field (hydrodynamic dispersion). In a (natural) variableaperture fracture, the heterogeneity of fluid velocities develops both along the fracture plane and across the fracture aperture. The part of hydrodynamic dispersion resulting from heterogeneity along the fracture plane is classically written as (Bodin et al. 2003b):

$$
D_{L 1}=\alpha u_{f}
$$

where dispersivity $\alpha[L]$ is proportional to the correlation length of the flow field. Note that Gelhar and Axness (1983) propose analytical expressions for the calculation of $\alpha$, from the 
correlation length and the standard deviation of the logarithm of the apertures in the fracture plane. Another part of solute dispersion results from the combination of molecular diffusion and velocity variations across the fracture aperture. This leads to the well-known Taylor-Aris dispersion, characterized by the dispersion coefficient (Dewey and Sullivan 1979):

$$
D_{L 2}=\frac{2}{105} \frac{u_{f}^{2} b^{2}}{D_{m}}
$$

The above expression is theoretically valid only beyond a critical travel time $\tau_{c}$, which corresponds to the minimum duration needed for a particle to experience the whole crosssectional parabolic profile of velocities across the fracture aperture. This critical time is proportional to a characteristic time of transverse diffusion: $\tau_{c} \propto b^{2} / D_{m}$. In other words, the solute must travel over a minimum distance $x_{c}>>u_{f} \tau_{c}$ before the Taylor-Aris dispersion regime is completely established. For $t<\tau_{c}$, the dispersion coefficient $D_{L 2}$ is time-dependent and its expression is given by Berkowitz and Zhou (1996):

$$
D_{L 2}(t)=\frac{u_{f}^{2} b^{2}}{D_{m}}\left[\frac{2}{105}-\sum_{n=1}^{\infty} \frac{18}{(n \pi)^{6}} \exp \left(-\frac{n^{2} \pi^{2} D_{m}}{b^{2}} t\right)\right]
$$

Ippolito et al. (1994) and Detwiler et al. (2000) showed both experimentally and numerically that dispersions along the fracture plane and across its variable aperture add up. Thus, the "bulk" dispersion coefficient can be written as:

$$
D_{f}=D_{m}+D_{L 1}+D_{L 2}
$$

In the program, the time-dependent Taylor-Aris dispersion of expression (40) is truncated to the third term. By applying the change of variable $t=x / u_{f}$, the spatial derivative of expression (41) yields the derivative of $D_{f}$ used in (10):

$$
\frac{\partial D_{f}}{\partial x}=\frac{u_{f}}{72 \pi^{4}} \exp \left(-\frac{\pi^{2} D_{m} x}{u_{f} b^{2}}\right)\left[1296+81 \exp \left(-3 \frac{\pi^{2} D_{m} x}{u_{f} b^{2}}\right)+16 \exp \left(-8 \frac{\pi^{2} D_{m} x}{u_{f} b^{2}}\right)\right]
$$


The dispersivity $\alpha$ in $D_{L 1}$ has been considered as constant for the above derivation of $D_{f}$. Note however that in the program, the value of $\alpha$ in each bond can be fixed as a user-defined constant, or as a function of the bond length:

$$
\alpha=\mu L^{\beta}
$$

where $\mu$ and $\beta$ are user-defined constants. The dispersivity $\alpha$ may also be considered as scaledependent, as suggested by numerous laboratory and field experiments, see e.g. Neuman (1990), Gelhar et al. (1992), Schulze-Makuch (2005). Three models of scale-dependent dispersivity are handled by the program: power law model, asymptotic model, and exponential model. These models are written, respectively, as (Pickens and Grisak 1981):

$$
\begin{gathered}
\alpha(x)=\varpi x^{\xi} \\
\alpha(x)=\Psi\left(1-\frac{\eta}{x+\eta}\right) \\
\alpha(x)=\Phi[1-\exp (-\kappa x)]
\end{gathered}
$$

where $\varpi[-], \xi[-]$ and $\kappa\left[L^{-1}\right]$ are user-defined constants, $\Psi[L]$ is the asymptotic dispersivity, $\eta[L]$ is the migration distance for which dispersivity is half its asymptotic value, and $\Phi[L]$ is the maximal value of dispersivity in the exponential model. The derivative and/or integral of $D_{f}$ in the case where both $D_{L 1}$ and $D_{L 2}$ are scale-dependent are straightforward and not developed here. Note that when simulating advective-dispersive transport in the bonds and matrix-diffusion, the mean fluid velocity $u_{f}$ in expressions (38-42) is replaced by the corrected velocity $u_{f}^{*}($ Eq. 26).

\section{Transport simulations on the network scale}

Transport simulations on the network scale are performed by tracking a set of particles injected into the flow field, until all the particles have left the network. For each particle, the TDRW algorithm is duplicated over the series of bonds experienced by the particle from its 
injection point up to its exit point at the downstream boundary of the network. Solute breakthrough curves are then calculated from the residence time distribution of the particles in the network.

\section{Solute injection}

In the program, the injection of particles may be performed either along the inlet boundary, or at any point of the backbone (i.e. the flowing part) of the fracture network. In the first case, each particle is injected into one of the inlet bonds chosen randomly according to probability density either uniform or proportional to the flow rate in the bond. In the second case, the injection point is specified by the user via a graphic interface. Both short-term injection of a finite mass and continuous injection of constant concentration are handled by the program. Short-term injection may be either instantaneous or exponential-decaying in time, and simulated by the release time $T_{\text {init }}$ assigned to each particle:

$$
\begin{gathered}
T_{\text {init }}=0 \text { if } \gamma=0 \\
T_{\text {init }}=-\frac{1}{\gamma} \log \left(U_{01}\right) \text { if } \gamma>0
\end{gathered}
$$

where $\gamma\left[T^{-1}\right]$ is a decay coefficient defining the release-rate of the injected mass and $U_{01}$ is a random number drawn from a uniform deviate between 0 and 1 . In the case where $\gamma>0$, the inlet solute-mass flux $F_{i}(t)\left[M \cdot T^{-1}\right]$ at each injection point $i$ obeys:

$$
F_{i}(t)=M_{i} \gamma \exp (-\gamma t)
$$

where $M_{i}[M]$ is the total solute-mass injected in the network at the point $i: \Sigma_{i} M_{i}=M_{0}$, with $M_{0}$ the total mass of solute injected into the network. If $N$ is the total number of particles used in the simulation, the solute-mass $m p_{i}$ assigned to each particle for its entry in the network through the point $i$ is equal to $M_{0} / N$. In the case of a continuous injection of constant concentration $C_{0}\left[M \cdot L^{-3}\right]$, the mass $m p_{i}$ is computed as: 


$$
m p_{i}=\frac{C_{0} Q_{i} \delta(t)}{N_{i}}
$$

where $Q_{i}\left[L^{3} \cdot T^{-1}\right]$ is the flow rate at the point $i$ in the network, and $N_{i}[-]$ is the number of particles entering the network through this point $\left(\sum_{i} N_{i}=N\right)$.

\section{Identification of elementary paths}

Once the injection points have been located, the program allows identifying all the elementary paths of the network. An elementary path is defined as a ranked series of connected bonds that a particle may experience to move from its injection point to the outlet boundary of the network. This computation step is optional because it is not required for the transport simulations. It enables (1) to visualize the set of bonds that are "available" for the solute motion, and (2) it may be useful for a breakthrough-curve computation based on a convolution of analytical solutions (see hereafter). However, in well-connected networks, the number of such paths may be much greater than the number of flowing bonds and the computational works needed to identify the paths is very time-consuming. As an example, several tens of hours were necessary with a $1 \mathrm{GHz}$ PC to identify $8 \times 10^{6}$ elementary paths on the transport problem illustrated in Fig. 3.

\section{Mass transfer through fracture intersections}

Rules for particle transition through fracture intersections must be defined according to a model of solute mass partitioning. Three particle routing methods are implemented in the program. These methods are based on either (1) the "perfect-mixing" model (Smith and Schwartz 1984), or (2) the "streamtube" model (Endo et al. 1984), or (3) the "diffusionalmixing" model (Park and Lee 1999). The perfect-mixing model is the simplest mixing rule and has been widely used in discrete transport simulations (see e.g. Smith and Schwartz (1984), Cacas et al. (1990a), Bradbury and Muldoon (1994)). In this model, molecular 
diffusion is assumed to ensure the homogenization of the solute mass fluxes at each fracture junction; therefore the same concentration value is observed at the entrance through the outlet bonds and mass sharing is proportional to the relative discharge flow rates. At the opposite limit, the streamtube model assumes that the solute molecules strictly follow the streamlines from the inflow bonds to the outflow bonds, with no mixing at the intersection. In this case, mass sharing depends on the configuration of inlet and outlet fluxes at the node. The streamtube model has been used by Robinson and Gale (1990), Wels and Smith (1994), Parney and Smith (1995), among others. The diffusional-mixing model, recently developed by Park and Lee (1999), is an alternative mixing rule between the perfect mixing model and the streamtube model. The solute molecules are assumed to follow the streamlines from the inflow bonds to the outflow bonds, but are allowed to diffuse between the streamlines, leading somehow to "partial-mixing" at the fracture junction. The mixing rate depends on the relative importance of advective versus diffusive mass transfer, expressed as a node-Péclet number $P e$, and defined as:

$$
P e=\frac{\bar{u} \sqrt{2} \bar{b}}{D_{m}}
$$

where $\bar{u}\left[L \cdot T^{-1}\right]$ is the mean fluid velocity in the inlet bonds connected to the junction, $\bar{b}[L]$ is the half mean-aperture of the inlet and outlet bonds, and $D_{m}\left[L^{2} \cdot T^{-1}\right]$ is the molecular diffusion of the solute in free water. Park and Lee (1999) have shown that the perfect-mixing and the streamtube models can be considered as two "end-member" cases of their diffusional-mixing model.

For the fracture networks handled by the SOLFRAC program, there is only one type of fracture junction for which the choice of the mixing model is important. This is the so-called "continuous junction" case, corresponding to the junction of two contiguous inlet bonds and 
two contiguous outlet bonds (Fig. 4). For all the other types of fracture junction (one inlet and three outlet bonds, three inlet and one outlet bonds, or one or more non-flowing "dead-end" bonds), it can be easily shown that the streamline patterns leads to the same mass partitioning whatever the mixing model used. Note that the particular case of "discontinuous junction" (i.e. two inlet and two outlet bonds on the opposite sides of an intersection), studied by Hull and Koslow (1986), may only occur if fluid sources or sinks are present within the flow domain, which is not provided for by the SOLFRAC program.

For all the "non-continuous" fracture junctions, particle-transition rules in the program are based on the perfect mixing model, and are written as:

$$
p_{i j}=\frac{Q_{j}}{\sum Q^{-}}
$$

where $p_{i j}[-]$ is the probability of particle transition from an inlet bond $i$ to an outlet bond $j, Q_{j}$ $\left[L^{3} \cdot T^{-1}\right]$ is the flow rate in the outlet bond $j$, and $\Sigma Q^{-}\left[L^{3} \cdot T^{-1}\right]$ is the sum of the discharge flow rates over all the outlet bonds connected to the junction of interest.

For the continuous junctions, particle-transition rules depend on the mixing model chosen by the user. With the perfect-mixing model, the particle transition probabilities are calculated according to Eq. (52). Note that with this model, mass sharing is not influenced by the inlet fluxes. With the streamtube model, mass sharing depends on both the inlet and outlet fluid fluxes. The solute tends to flow preferentially into the outlet bond that is directly contiguous to the inlet where it comes from. Referring to the case illustrated in Fig. 4 where the solute particles come from the inlet bond $i=2$, one can distinguish two possibilities (Park and Lee 1999):

$$
Q_{2} \leq Q_{3} \Rightarrow\left\{\begin{array}{l}
p_{23}=1 \\
p_{24}=0
\end{array}\right.
$$




$$
Q_{2}>Q_{3} \Rightarrow\left\{\begin{array}{c}
p_{23}=\frac{Q_{3}}{Q_{2}} \\
p_{24}=\frac{Q_{2}-Q_{3}}{Q_{2}}
\end{array}\right.
$$

Using the same flow pattern but with solute particles coming from the inlet bond $i=1$, the transition probabilities are written as:

$$
\begin{gathered}
Q_{1} \leq Q_{4} \Rightarrow\left\{\begin{array}{l}
p_{13}=0 \\
p_{14}=1
\end{array}\right. \\
Q_{1}>Q_{4} \Rightarrow\left\{\begin{array}{c}
p_{13}=\frac{Q_{1}-Q_{4}}{Q_{1}} \\
p_{14}=\frac{Q_{4}}{Q_{1}}
\end{array}\right.
\end{gathered}
$$

The mathematical expressions for the diffusional-mixing model of Park and Lee (1999) are somewhat bigger, but do not entail any calculation problem. Referring to the above two cases, the transition probabilities are written as:

$$
\begin{aligned}
& p_{23}=\left.\frac{Q_{3} C_{3}}{Q_{3} C_{3}+Q_{4} C_{4}}\right|_{C_{1}=0} \\
& p_{24}=\left.\frac{Q_{4} C_{4}}{Q_{3} C_{3}+Q_{4} C_{4}}\right|_{C_{1}=0} \\
& p_{13}=\left.\frac{Q_{3} C_{3}}{Q_{3} C_{3}+Q_{4} C_{4}}\right|_{C_{2}=0} \\
& p_{14}=\left.\frac{Q_{4} C_{4}}{Q_{3} C_{3}+Q_{4} C_{4}}\right|_{C_{2}=0}
\end{aligned}
$$

with the expressions of $C_{3}$ and $C_{4}$ for $Q_{1} \leq Q_{4}$ :

$$
\begin{gathered}
C_{3}=C_{0}+\frac{C_{2}-C_{0}}{\Pi_{32}}\left[\frac{\exp \left(-\Pi_{22}^{2}\right)-\exp \left(-\Pi_{\delta 2}^{2}\right)}{\sqrt{\pi}}+\Pi_{22} \operatorname{erf}\left(\Pi_{22}\right)-\Pi_{\delta 2} \operatorname{erf}\left(\Pi_{\delta 2}\right)\right] \\
C_{4}=C_{0}+\frac{C_{1}-C_{0}}{\Pi_{41}}\left[\frac{\exp \left(-\Pi_{11}^{2}\right)-\exp \left(-\Pi_{\delta 2}^{2}\right)}{\sqrt{\pi}}+\Pi_{11} \operatorname{erf}\left(\Pi_{11}\right)-\Pi_{\delta 2} \operatorname{erf}\left(\Pi_{\delta 2}\right)\right]
\end{gathered}
$$


while, for $Q_{1}>Q_{4}$ :

$$
\begin{gathered}
C_{3}=C_{0}+\frac{C_{2}-C_{0}}{\Pi_{32}}\left[\frac{\exp \left(-\Pi_{22}^{2}\right)-\exp \left(-\Pi_{\delta 1}^{2}\right)}{\sqrt{\pi}}+\Pi_{22} \operatorname{erf}\left(\Pi_{22}\right)-\Pi_{\delta 1} \operatorname{erf}\left(\Pi_{\delta 1}\right)\right] \\
C_{4}=C_{0}+\frac{C_{1}-C_{0}}{\Pi_{41}}\left[\frac{\exp \left(-\Pi_{11}^{2}\right)-\exp \left(-\Pi_{\delta 1}^{2}\right)}{\sqrt{\pi}}+\Pi_{11} \operatorname{erf}\left(\Pi_{11}\right)-\Pi_{\delta 1} \operatorname{erf}\left(\Pi_{\delta 1}\right)\right]
\end{gathered}
$$

and where:

$$
\begin{gathered}
C_{0}=\frac{\sqrt{u_{1}} C_{1}+\sqrt{u_{2}} C_{2}}{\sqrt{u_{1}}+\sqrt{u_{2}}} \\
\Pi_{i j}=\frac{Q_{i}}{\sqrt{4 \sqrt{2} D_{m} u_{j} b_{m}}} \\
\Pi_{\delta i}=\frac{Q_{3}-Q_{2}}{\sqrt{4 \sqrt{2} D_{m} u_{i} b_{m}}}
\end{gathered}
$$

$D_{m}\left[L^{2} \cdot T^{-1}\right]$ is the molecular diffusion of the solute, $b_{m}[L]$ the mean aperture of the bonds connected to the fracture junction, and $u_{i}\left[L \cdot T^{-1}\right]$ the fluid velocity in bond $i$. Note that the above expressions are those provided by Mourzenko at al. (2002) who corrected a few misprints of the initial work by Park and Lee (1999).

Many attempts, either experimental, analytical, or numerical, have been undertaken by several authors to determine the best suited mixing-model for simulating solute mass partitioning at continuous fracture junctions (Hull and Koslow 1986; Robinson and Gale 1990; Berkowitz et al. 1994; Park and Lee 1999; Mourzenko et al. 2002). The most recent is that by Mourzenko et al. (2002), who performed three-dimensional particle tracking simulations over both parallel-plate and rough-walled fracture intersections. The following conclusions can be drawn from their results: 
1. In the case of a parallel-plate fracture intersection, the streamtube model is suited for node-Péclet numbers $P e \geq 30$ (see Eq. 51). However, the sharp mass partitioning predictions in expressions (53) and (55) are unrealistic when the difference between the flow rates $\left(Q_{2}\right.$ and $\left.Q_{3}\right)$ or $\left(Q_{1}\right.$ and $\left.Q_{4}\right)$ is very small. The diffusional-mixing model is more universal since it applies fairly well for $P e \geq 10$. The perfect-mixing approximation is only valid for $P e$ values close to unity. For very low Péclet values, (i.e. $P e<<1$ ), the solute transfer through the fracture junction becomes mostly diffusive and none of the above three mixing models is valid. Note that such eventuality occurs rarely in practice.

2. In the case of a rough-walled fracture intersection, the streamtube, diffusional mixing, and perfect mixing models remain qualitatively valid over $P e$ ranges similar to those specified above for a parallel-plate fracture intersection. However, the streamtube and diffusional mixing models slightly underestimate the solute mixing at fracture intersection for large Péclet numbers.

\section{Breakthrough curve computation}

Solute breakthrough curves are calculated from the residence time distribution of the particles in the network, according to the following algorithm:

1. Determination of the minimum and maximum residence times $t_{\min }, t_{\max }$ of the whole set of particles;

2. Discretisation of the time-interval $\left[t_{\min }-t_{\max }\right]$ in $N$ time steps of duration $\Delta t$;

3. Summation of the mass associated with the particles leaving the network during each time step $\Delta t_{n}(n=1 . . N)$ :

$$
m\left(\Delta t_{n}\right)=\sum_{j=1}^{N p_{n}} m p_{\text {out }}(j)
$$


where $N p_{n}$ is the number of particles leaving the network during the time step $\Delta t_{n}$, and $m p_{\text {out }}(j)$ is the mass of the $j^{\text {th }}$ particle leaving the network during $\Delta t_{n}$ (see Eq. 34);

4. Calculation of the mean concentration at the outlet boundary of the network for each time step. In the case of short-term injection of finite mass $M_{0}$ (see above):

$$
c_{1}\left(\Delta t_{n}\right)=\frac{m\left(\Delta t_{n}\right)}{\Delta t \sum Q_{\text {out }}}
$$

where $\Sigma Q_{\text {out }}\left[L^{3} \cdot T^{-1}\right]$ is the sum of the discharge flow rate over all the bonds connected to the outlet boundary of the network. In the case of a continuous injection of constant concentration $C_{0}$ (see above):

$$
C_{2}\left(\Delta t_{n}\right)=\int_{t_{\min }}^{t_{\min }+n \Delta t} c_{1}(t) d t
$$

In the program, the integral in expression (67) is numerically evaluated with an evolutive Simpson's rule (see Press et al. (1993) pp 132-134).

During the transport simulations, the history of each particle in the network is recorded as a series of data pairs describing the succession of the nodes encountered, and the arrival times of the particle at these nodes. These data may be used to compute the solute breakthrough curve at any observation node specified by the user, according to an algorithm similar to that described above. Note also that these data pairs further enable to analyze the solute-plume dispersion at the network scale (see hereafter).

The accuracy of the simulated breakthrough curves depends on both the number $N$ of times intervals (i.e. the number of points $c\left(\Delta t_{n}\right)$ on the graph), and the number of particles used in the simulation. The number of particles to be used increases with $N$ because a minimum number of particles is required within each time interval in order to ensure the convergence of 
$c\left(\Delta t_{n}\right)$. Furthermore, the number of particles needed increases with the complexity of the network. From a practical point of view, it is difficult to estimate the optimum number of particles to be used in a given network. An empirical method consists in repeating simulations, increasing each time the number of particles, up to reach no significant difference between the simulated breakthrough curves. As an example, about $10^{4}$ particles are required for simulating accurately the transport problem illustrated in Fig. 3, with 100 points on the breakthrough curve. Note that in a Monte Carlo framework involving a large number of simulations, the number of particles may be lower because the oscillations resulting from the discrete nature of the particles are random and cancel each other when ensemble statistics are computed (see e.g. Hassan and Mohamed 2003).

\section{Verification problems}

The purpose of this chapter is to verify the accuracy of the program through comparisons with analytical and semi-analytical solutions of solute transport in fractured media. Although not mentioned in previous papers, the SOLFRAC program has been used by Delay and Bodin (2001) and Bodin et al. (2003c) for assessing the accuracy of the TDRW method through several basic transport problems. Delay and Bodin (2001) first addressed the case of nonreactive solute transport in a single fracture-matrix system. The transport processes considered were advection-dispersion in the fracture plane, and matrix diffusion. Simulation results compared very well with the analytical solution of Sudicky and Frind (1982). This model verification was extended by Bodin et al. (2003c) to the case of reactive solute transport, including sorption on the fracture walls and radioactive decay. Bodin et al. (2003c) also showed the accuracy of the TDRW method (and of the SOLFRAC code) for simulating advection and hydrodynamic dispersion in a synthetic fracture network with sharp contrasts in 
dispersion coefficients. The series of test problems presented in this section has been designed to verify the accuracy of the program in transport scenarios that have not yet been addressed.

\section{Tests SF1 and SF2: Scale-dependent dispersion in a single fracture}

The purpose of the tests SF1 and SF2 is to investigate the ability of the program to deal with scale-dependent dispersion within the bonds of a fracture network. An advection-dispersion problem in a single fracture is addressed and dispersion is assumed to increase linearly (test SF1) or exponentially (test SF2) with distance along the fracture axis. A source of solute of constant strength is assumed to supply a continuous injection of constant concentration at the fracture inlet. Analytical solutions to the above-described problems were developed by Yates (1990, 1992). The values of the parameters used for the calculation of both the analytical curves and SOLFRAC simulations are listed in Table 1. As shown in Fig. 5, simulations and analytical solutions are in very good agreement.

\section{Test DFN1: Reactive solute transport in a fracture network}

The test DFN1 performed over a synthetic discrete fracture network involves the following mechanisms: (1) advection and hydrodynamic dispersion in the fractures, (2) matrix diffusion, (3) solute sorption on the fracture walls and in the matrix, and (4) mass sharing at fracture intersections. The network size is $350 \times 350 \mathrm{~m}$, and the constant hydraulic head values on the top and bottom boundaries are fixed to $100 \mathrm{~m}$ and $99 \mathrm{~m}$, respectively. The flow takes place within two orthogonal sets of fractures, yielding 71 flowing bonds (Fig. 6). The fracture apertures and widths are constant over the network and set up to $2 b=2.5 \times 10^{-4} \mathrm{~m}$ and $W=1$ $\mathrm{m}$, respectively. A mass $m_{0}=10^{-2} \mathrm{~g}$ of solute is instantaneously injected at the inlet $B_{1}$ of the network (see Fig. 6). The values of transport parameters in the fractures and the rock matrix 
are listed in Table 2. The theoretical breakthrough curve $c_{\text {out }}(t)$ at the outlet of the network is calculated as the summation of mass fluxes from each elementary flow path in the network (Bodin et al., 2003c):

$$
C_{\text {out }}(t)=\frac{\sum_{i=1}^{N_{\text {EP }}} F_{i}(t)}{Q_{\text {out }}}
$$

where $N_{E P}$ is the number of elementary paths starting from the injection point $\left(N_{E P}=1800\right.$ in the current problem), $F_{i}(t)\left[M \cdot T^{-1}\right]$ is the solute mass flux in the $i^{\text {th }}$ elementary path, and $Q_{\text {out }}$ $\left[L^{3} \cdot T^{-1}\right]$ is the total flow rate at the outlet boundary of the network. The solute mass flux $F_{i}(t)$ can be expressed as a convolution product of the probability density functions $\mathfrak{I}_{n}\left[T^{1}\right]$ of residence times in each bond of the elementary path $i$ :

$$
F_{i}(t)=m_{0}\left(\prod_{n=1}^{N_{i}-1} p_{n, n+1}\right) \mathfrak{I}_{1}(t) * \mathfrak{I}_{2}(t) \cdots * \mathfrak{J}_{N_{i}}(t)
$$

where $N_{i}$ is the number of bonds in the elementary path $i$, and $p_{n, n+1}$ is the fraction of solute mass in bond $n$ that flows into bond $n+1$, this fraction depending on the flow configuration and on the mixing model at the fracture intersection (see expressions 52, 53-56, and 57). Because the transport problem DFN1 involves both advection-dispersion in fractures and matrix diffusion, the convolution product in (69) cannot be simply replaced by an equivalent probability density function as the one developed by Bodin et al. (2003c). We rather propose to use the Laplace transform of $\mathfrak{I}_{n}(\mathrm{t})$, which is easily derived from the work by Tang et al. (1981):

$$
\overline{\mathfrak{I}}_{n}(s)=\exp (v L) \exp \left[-v L\left\{1+\beta^{2}\left(\frac{s^{1 / 2}}{A}+s\right)\right\}^{1 / 2}\right]
$$

where

$$
v=\frac{u_{n}}{2 D_{n}}
$$




$$
\begin{gathered}
A=\frac{b R_{f}}{\sqrt{\left(\theta_{m}+\rho_{m} k_{m}\right) D_{e}}} \\
\beta^{2}=\frac{4 R_{f} D_{n}}{u_{n}^{2}} \\
R_{f}=1+k_{f} / b
\end{gathered}
$$

where $s[-]$ is the Laplace parameter, $L[L]$ is the length of the bond $n, u_{n}\left[L \cdot T^{-1}\right]$ and $D_{n}\left[L^{2} \cdot T^{-1}\right]$ are the flow velocity and the dispersion coefficient in the bond, respectively, and $R_{f}[-]$ is a retardation coefficient due to solute sorption on the fracture walls. As stated above, the Laplace transform of a convolution is the product of the individual transforms. Thus, the Laplace transform of the solute mass flux in the $i^{\text {th }}$ elementary path is:

$$
\bar{F}_{i}(s)=m_{0}\left(\prod_{n=1}^{N_{i}-1} p_{n, n+1}\right)\left(\prod_{n=1}^{N_{i}} \overline{\mathfrak{J}}_{n}(s)\right)
$$

The substitution of the inverse transform of $\bar{F}_{i}(s)$ for $F_{i}(t)$ in (68) yields the following semianalytical (SA) solution:

$$
c_{\text {out }}(t)=\frac{\sum_{i=1}^{N_{E P}} L^{-1}\left\{\bar{F}_{i}(s)\right\}}{Q_{\text {out }}}=\frac{L^{-1}\left\{\sum_{i=1}^{N_{E P}} \bar{F}_{i}(s)\right\}}{Q_{\text {out }}}=\frac{m_{0}}{Q_{\text {out }}} L^{-1}\left\{\sum_{i=1}^{N_{E P}}\left[\left(\prod_{n=1}^{N_{i}-1} p_{n, n+1}\right)\left(\prod_{n=1}^{N_{i}} \overline{\mathfrak{I}}_{n}(s)\right)\right]\right\}
$$

For the test DFN1, the inverse Laplace transform $L^{-1}\{\}$ in (76) has been numerically evaluated using the MATLAB ${ }^{\circledR}$ routine "Invlap.m" written by Hollenbeck (1998), which is based on the De Hoog et al. (1982) algorithm. Both SA and SOLFRAC breakthrough curves have been computed using successively the perfect-mixing model, streamtube model, and diffusionalmixing model for mass partitioning at fracture junctions. As shown in Fig. 7, SA and SOLFRAC results coincide very well in each case.

\section{Macroscopic time- and scale-analysis of solute transport}


As stated earlier, the program can analyze various transport features on the network scale, either from the spatial distribution of particles at a given time or from the residence time distribution (RTD) of the particles in the network. These transport features are: (1) timeevolution of the mean position of the particle cloud, (2) time-evolution of the longitudinal and transverse variance of the particle cloud, (3) computation of the macroscopic longitudinal and transverse dispersion coefficients at a given time, (4) time-evolution of the macroscopic dispersion, (5) scale-evolution of the macroscopic dispersion according to the mean position of the particle cloud, and (6) evolution of the dilution index according to the mean position of the particle cloud. The term "macroscopic dispersion" is used here by analogy to transport in porous media, and describes the spreading of the solute/particle plume on the network scale. This spreading results from the cumulated effects of the flow-field heterogeneity on the network scale (controlled by the fracture network geometry), the mass sharing at fracture intersections, and the transport processes on the bond-scale. In the "ideal case" of a homogeneous 1D transport problem, the following relations hold:

$$
\begin{gathered}
\sigma_{t}^{2}=\frac{2 D_{F} \Delta x}{U^{3}} \Leftrightarrow D_{F}=\frac{U^{3} \sigma_{t}^{2}}{2 L} \\
\sigma_{x}^{2}=2 D_{F} t \quad \Leftrightarrow \quad D_{F}=\frac{\sigma_{x}^{2}}{2 t}
\end{gathered}
$$

where $\sigma_{t}^{2}\left[T^{2}\right]$ is the variance of the residence time distribution of the particles for a transportlength $L, \sigma_{x}^{2}\left[T^{2}\right]$ is the variance of the spatial distribution of the particles at a given time $t, D_{F}$ $\left[L^{2} \cdot T^{-1}\right]$ is the (Fickian) dispersion coefficient, and $U\left[L \cdot T^{-1}\right]$ is the mean flow velocity. The macroscopic dispersion (or "macrodispersion") coefficients computed in SOLFRAC rely on various definitions, which are all basically based on the relations above. Two expressions are based on the Residence Time Distribution (RTD) between injection and one location of the network: 


$$
\begin{gathered}
D\left(\Delta l_{i o}\right)=\frac{\Delta l_{i o}^{2}}{2 t_{m}^{3}} \sigma_{t}^{2} \\
D\left(\Delta l_{i o}\right)=\frac{\Delta l_{i o}}{8}\left(\frac{1-t_{16} / t_{m}}{\sqrt{t_{16}}}-\frac{1-t_{84} / t_{m}}{\sqrt{t_{84}}}\right)^{2}
\end{gathered}
$$

where $\Delta l_{i o}[\mathrm{~L}]$ is the longitudinal distance between injection and observation points in the network, $t_{m}[T]$ and $\sigma_{t}[T]$ are the mean and standard deviation of the RTD, respectively, and $t_{16}$ and $t_{84}$ are the time values for which the cumulative probability density function of the particle RTD is equal to 0.16 and 0.84 , respectively. Expression (80) was first proposed by Fried and Combarnous (1971), and is similar to Eq. (79) except that the calculation of the dispersion coefficient relies on a truncated RTD. This truncation forces the relative influence of both rising and lowering parts of the breakthrough curve to balance in the computation of $D$, which may be useful when the time-evolution of concentrations exhibits an extensive tailing. The calculation of a macroscopic dispersion coefficient from the spatial distribution of particles at a given time may also be based on different approaches. Let us denote $D_{x x}$ and $D_{y y}$ the longitudinal and transverse macrodispersion coefficients, respectively. The program computes $D_{x x}$ and $D_{y y}$ from either an "apparent" or "effective" definition (Dagan 1989; Jussel et al. 1994):

$$
\begin{gathered}
D_{x x_{-} a p p}\left(T_{o b s}\right)=\frac{\sigma_{x}^{2}\left(T_{o b s}\right)}{2 T_{o b s}} \\
D_{y y_{-} a p p}\left(T_{o b s}\right)=\frac{\sigma_{y}^{2}\left(T_{o b s}\right)}{2 T_{o b s}} \\
D_{x x_{-} e f f}\left(T_{o b s}\right)=\left.\frac{1}{2} \frac{\partial \sigma_{x}^{2}}{\partial t}\right|_{t=T_{o b s}}=\frac{\sigma_{x}^{2}\left(T_{o b s}+\Delta t / 2\right)-\sigma_{x}^{2}\left(T_{o b s}-\Delta t / 2\right)}{2 \Delta t} \\
D_{y y_{\_} e f f}\left(T_{o b s}\right)=\left.\frac{1}{2} \frac{\partial \sigma_{y}^{2}}{\partial t}\right|_{t=T_{o b s}}=\frac{\sigma_{y}^{2}\left(T_{o b s}+\Delta t / 2\right)-\sigma_{y}^{2}\left(T_{o b s}-\Delta t / 2\right)}{2 \Delta t}
\end{gathered}
$$


where $\sigma_{x}^{2}\left(T_{o b s}\right)$ and $\sigma_{y}^{2}\left(T_{o b s}\right)$ are the spatial-variance of the particle cloud projected on the $x$ direction parallel to the flow gradient and $y$-direction perpendicular to $x$, at time $T_{o b s}$. Coefficients $D_{\text {x__app }}$ and $D_{\text {y__app }}$ are termed "apparent" because the analysis assumes spatial homogeneity along the travel distance, i.e. the definition is similar to that in (78) of a homogeneous Fickian dispersion. On the other hand, coefficients $D_{\text {x__eff }}$ and $D_{y y \_}$eff are termed "effective" because their calculation only considers the temporal-increment in the plume development without any reference to homogeneity. In the program, the duration of $\Delta t$ in (83) and (84) is that of the time-steps used for the computation of breakthrough curves (see Eq. 66). SOLFRAC enables to analyze the time-evolution of macrodispersion by computing $D_{x x_{\_} a p p}, D_{y y \_a p p}, D_{x x \_e f f}$, and $D_{y y \_e f f}$ for several $T_{o b s}$ values, evenly distributed between 0 and the first particle arrival-time at the network outlet. It is also possible to analyze the scaleevolution of macrodispersion by plotting $D_{\text {xx_app }}$ and $D_{\text {xx_eff }}$ values with respect to the $x$-mean position of the particle cloud for the same $T_{o b s}$ values. Note that performing an injection over the whole inlet boundary of the network, which makes the particles to experience most of the flowing bonds, is preferable for analyzing the longitudinal macrodispersion $D_{x x}$. On the other hand, a single injection point is preferable for analyzing the transverse macrodispersion $D_{y y}$, in order to ensure that $\sigma_{y}^{2}=0$ at $t=0$. This injection point may be randomly chosen among the nodes located at the inlet boundary of the network.

The concept of "dilution index" was developed by Kitanidis (1994) to better differentiate between spreading and dilution in heterogeneous media. The dilution index characterizes the volume of porous medium occupied by the solute at a given time. Mathematically, it is defined as:

$$
E(t)=\exp \left[-\int_{V} \frac{c(\mathbf{x}, t)}{M(t)} \ln \left(\frac{c(\mathbf{x}, t)}{M(t)}\right) d V\right]
$$


where $V$ is the volume (or length) of the studied system, $c(\mathbf{x}, t)$ is the solute concentration at location $\mathbf{x}$, and $M(t)$ is the total mass of solute in the system at time $t$ :

$$
M(t)=\int_{V} c(\mathbf{x}, t) d V
$$

As pointed out by Park and Lee (2001), the dilution process in fracture networks is closely related to the solute mass partitioning among the multiple available flow paths. Today, it is well known that solute transport in natural fracture networks is often channelised, i.e. most of the mass transfer occurs in a limited number of flow paths (see e.g. Tsang and Neretnieks (1998) and references therein). Park and Lee (2001) suggested that the dilution index might be used as a quantitative measurement of the degree of channelised transport in fractured media. The program enables to compute curves showing the evolution of the dilution index with respect to the mean position of the particle cloud. As suggested by Park and Lee (2001), this type of plot is useful to analyze the dilution features in a fracture network. In the program, the dilution index is calculated as follows:

$$
E(t)=\exp \left[-\sum_{n=1}^{N_{B}} \frac{N P_{n}(t)}{N P_{t o t}(t)} \ln \left(\frac{N P_{n}(t)}{N P_{t o t}(t)}\right)\right]
$$

where $N_{B}$ is the total number of flowing bonds in the fracture network (i.e. the number of pipes in the backbone of the network), $N P_{n}(t)$ is the number of particles in bond $n$ at time $t$, and $N P_{\text {tot }}(t)$ the total number of particles in the whole network at time $t$.

\section{Summary and conclusion}

In 1993, Smith and Schwartz (1993) rightly argued that the computational constraints on the total number of fractures that can be included in a discrete network severely limited the applicability of this modelling approach to practical cases. This was justified a dozen years ago, but the computation capacities have strongly increased and today, representative discrete models become affordable to handle transport problems on the scale of a reservoir. However, 
it is important to note that the question of parameterisation remains unanswered but still crucial since numerical simulations rely on available data (see e.g. Smith et al. 1997).

The software presented in this paper performs fast simulations of solute transport in complex 2D fracture networks. Comparisons between numerical results and analytical breakthrough curves for synthetic test problems have proven the accuracy of the model. Transport simulations are free of numerical dispersion (Lagrangian method) and avoid mass balance discrepancies stemming from dispersion contrast at fracture intersections. Compared to other Lagrangian models, both local dispersion and diffusion into immobile zones are explicitly accounted for. The immobile zones considered here are (1) the rock matrix, and (2) the stagnant zones within the fracture plane. Other mechanisms such as radioactive decay, sorption reactions or scale-dependent dispersion are also handled. The SOLFRAC program should become a convenient tool to evaluate how these mechanisms influence the macroscopic transport behaviour of the network. All the modelling concepts and numerical methods presented in this work may easily be transposed from the 2D- to the 3D-space (i.e. pipe networks interconnected in 3D space), for simulating solute transport in realistic fracture networks or in small rock samples with pore space approached by pipe networks.

Note that input files corresponding to single fracture problems are also very simple to type with any text editor. Thus, the SOLFRAC program could be used, as is the case with analytical solutions, to interpret laboratory or field tracer test experiments performed in single fractures. In this case, the program allows dealing with tracer tests including hydrodynamic dispersion and matrix diffusion without computation of inverse Laplace transforms. The computation method also deals with additional mechanisms such as scale-dependent 
dispersion, or solute diffusion into stagnant zones, for which analytical solutions are not available.

Acknowledgments. We are grateful to the "French National Program for Research in Hydrology” (PNRH) for the financial support of this work. 


\section{References}

Andersson, J. and Dverstorp, B., 1987. Conditional simulations of fluid flow in threedimensional networks of discrete fractures. Water Resour. Res., 23(10): 1876-1886.

Andersson, J. and Thunvik, R., 1986. Predicting mass transport in discrete fracture networks with the aid of geometrical field data. Water Resour. Res., 22(13): 1941-1950.

Arnold, B.W., Zhang, H. and Parsons, A.M., 2000. Effective-porosity and dual-porosity approaches to solute transport in the saturated zone at Yucca Mountain: implications for repository performance assessment. In: B. Faybishenko, P.A. Witherspoon and S.M. Benson (Editors), Dynamics of fluids in fractured rock. Geophysical Monograph Series. American Geophysical Union, Washington, DC, pp. 313-322.

Banton, O., Delay, F. and Porel, G., 1997. A new Time Domain Random Walk method for solute transport in 1-D heterogeneous media. Ground Water, 35(6): 1008-1013.

Berkowitz, B., Bear, J. and Braester, C., 1988. Continuum models for contaminant transport in fractured porous formations. Water Resour. Res., 24(8): 1225-1236.

Berkowitz, B., Naumann, C. and Smith, L., 1994. Mass transfer at fracture intersections: An evaluation of mixing models. Water Resour. Res., 30(6): 1765-1773.

Berkowitz, B. and Zhou, J., 1996. Reactive solute transport in a single fracture. Water Resour. Res., 32(4): 901-913.

Bernard, S. 2002. Le logiciel MODFRAC : simulation de réseaux de fractures 2D et de l'écoulement associé. [MODFRAC: a program for simulating steady-state flow in 2D random fracture networks]. Geosciences DEA report (in French). University of Poitiers, France.

Bibby, R., 1981. Mass transport of solutes in dual-porosity media. Water Resour. Res., 17(4): 1075-1081. 
Billaux, D., Chiles, J.P., Hestir, K. and Long, J.C.S., 1989. Three-dimensional statistical modeling of a fractured rock mass. An example from the Fanay-Augères Mine. Int. J. Rock Mech. Min. Sci. Geomech. Abstr., 26(3/4): 281-299.

Bodin, J., Delay, F. and de Marsily, G., 2003a. Solute transport in fissured aquifers: 1. Fundamental mechanisms. Hydrogeol. J., 11: 418-433.

Bodin, J., Delay, F. and de Marsily, G., 2003b. Solute transport in fissured aquifers: 2. Mathematical formalism. Hydrogeol. J., 11: 434-454.

Bodin, J., Porel, G. and Delay, F., 2003c. Simulation of solute transport in discrete fracture networks using the time domain random walk method. Earth Planet. Sci. Lett., 6566: $1-8$.

Bodin, J. and Razack, M., 1999. L'analyse d'images appliquée au traitement automatique de champs de fractures. Propriétés géométriques et lois d'échelles. [Use of image analysis techniques for the automatic processing of fracture maps. Geometrical properties and scaling laws]. Bull. Soc. Géol. Fr., 170(4): 579-593.

Bour, O. and Davy, P., 1997. Connectivity of random fault networks following a power law fault length distribution. Water Resour. Res., 33(7): 1567-1583.

Bradbury, K.R. and Muldoon, M.A., 1994. Effects of fracture density and anisotropy on delineation of wellhead-protection areas in fractured-rock aquifers. Appl. Hydrogeol., 3: $17-23$.

Cacas, M.C., Ledoux, E., de Marsily, G., Barbreau, A., Calmels, P., Gaillard, B., and Margritta, R., 1990a. Modeling fracture flow with a stochastic discrete fracture network: Calibration and validation, 2, The transport model. Water Resour. Res., 26(3): 491-500.

Cacas, M.C., Ledoux, E., de Marsily, G., Tillie, B., Barbreau, A., Calmels, P., Durand, E., Feuga, B., and Peaudecerf, P., 1990b. Modeling fracture flow with a stochastic 
discrete fracture network: Calibration and validation, 1, The flow model. Water Resour. Res., 26(3): 479-489.

Cowie, P.A., Knipe, R.J. and Main, I.G. (Editors), 1996. Scaling laws for fault and fracture populations - Analyses and applications. J. Struct. Geol. (Special Issue), 18(2-3): 135383.

Dagan, G. 1989. Flow and transport in porous formation. Springer-Verlag, New York. de Dreuzy, J.-R., Davy, P. and Bour, O., 2000. Percolation parameter and percolationthreshold estimates for three-dimensional random ellipses with widely scattered distributions of eccentricity and size. Physical Rev. E., 62(5): 5948-5952.

de Dreuzy, J.-R., Davy, P. and Bour, O., 2001a. Hydraulic properties of two-dimensional random fracture networks following a power law length distribution, 1. Effective connectivity. Water Resour. Res., 37(8): 2065-2078.

de Dreuzy, J.-R., Davy, P. and Bour, O., 2001b. Hydraulic properties of two-dimensional random fracture networks following a power law length distribution, 2. Permeability of networks based on lognormal distribution of apertures. Water Resour. Res., 37(8): 2079-2095.

de Dreuzy, J.-R., Davy, P. and Bour, O., 2002. Hydraulic properties of two-dimensional random fracture networks following power law distributions of length and aperture. Water Resour. Res., 38(12), 1276, doi: 10.1029/2001WR001009.

de Dreuzy, J.-R. , Darcel, C., Davy, P., and Bour, O., 2004. Influence of spatial correlation of fracture centers on the permeability of two-dimensional fracture networks following a power law length distribution. Water Resour. Res. 40(1). W01502, doi:

10.1029/2003WR002260.

De Hoog, F.R., Knight, J.H. and Stokes, A.N., 1982. An improved method for numerical inversion of Laplace transforms. SIAM J. Sci. Stat. Comput., 3(3): 357-366. 
Delay, F. and Bodin, J., 2001. Time domain random walk method to simulate transport by advection-dispersion and matrix diffusion in fracture networks. Geophys. Res. Lett., 28(21): 4051-4054.

Dershowitz, W.S. and Fidelibus, C., 1999. Derivation of equivalent pipe network analogues for three-dimensional discrete fracture networks by the boundary element method. Water Resour. Res., 35(9): 2685-2691.

Dershowitz, W.S., Thorsten, E., Follin, S. and Andersson, J., 1999. SR 97 - Alternative models project. Discrete fracture network modelling for performance assessment of Aberg. SKB Rapport R. 99-43. Swedish Nuclear Fuel and Waste Management CO. Stockholm, Sweden.

Detwiler, R.L., Rajaram, H. and Glass, R.J., 2000. Solute transport in variable-aperture fractures: An investigation of the relative importance of Taylor dispersion and macrodispersion. Water Resour. Res., 36(7): 1611-1625.

Dewey, R. and Sullivan, P.J., 1979. Longitudinal dispersion in flows that are homogeneous in the streamwise direction. Zeitschrift fur angewandte Mathematik und Physik (Z. angew. Math. Phys.), 30: 601-612.

Dverstorp, B., Andersson, J. and Nordqvist, W., 1992. Discrete fracture network interpretation of field tracer migration in sparsely fractured rock. Water Resour. Res., 28(9): 2327-2343.

Endo, H.K., Long, J.C.S., Wilson, C.R. and Witherspoon, P.A., 1984. A model for investigating mechanical transport in fracture networks. Water Resour. Res., 20(10): 1390-1400.

Fried, J.J. and Combarnous, M.A., 1971. Dispersion in porous media. Advances in Hydrosciences, 7: 167-282. 
Gburek, W.J. and Folmar, G.J., 1999. Patterns of contaminant transport in a layered fractured aquifer. J. Contam. Hydrol., 37(1-2): 87-109.

Gelhar, L.W. and Axness, C.L., 1983. Three-dimensional stochastic analysis of macrodispersion in aquifers. Water Resour. Res., 19(1): 161-180.

Gelhar, L.W., Welty, C. and Rehfeldt, K.R., 1992. A critical review of data on field-scale dispersion in aquifers. Water Resour. Res., 28(7): 1955-1974.

Gerke, H.H. and van Genuchten, M.T., 1996. Macroscopic representation of structural geometry for simulating water and solute movement in dual-porosity media. Adv. Water Res., 19(6): 343-357.

Gill, P.E., Murray, W. and Wright, M.H., 1991. Numerical Linear Algebra and Optimization, volume 1. Addison-Wesley Publishing Company, Redwood City, CA.

Grandi, G.M. and Ferreri, J.C., 1994. Transport of radionuclides in isolated fractures in crystalline rocks. Int. J. Numer. Methods Fluids, 18(11): 1107-1119.

Guimera, J., Vives, L. and Carrera, J., 1995. A discussion of scale effects on hydraulic conductivity at a granitic site (El Berrocal, Spain). Geophys. Res. Lett., 22(11): 14491452.

Hassan, A. E., and Mohamed, M. M., 2003. On using particle tracking methods to simulate transport in single-continuum and dual continua porous media. J. Hydrol., 275: 242260.

Hollenbeck, K., 1998. INVLAP.M: A matlab function for numerical inversion of Laplace transforms by the de Hoog algorithm. http://www.mathtools.net/files/net/invlap.zip.

Hull, L.C. and Koslow, K.N., 1986. Streamline routing through fracture junctions. Water Resour. Res., 22(12): 1731-1734.

Huseby, O., Thovert, J.-F. and Adler, P.M., 2001. Dispersion in three-dimensional fracture networks. Phys. Fluids, 13(3): 594-616. 
Huyakorn, P.S., Lester, B.H. and Mercer, J.W., 1983a. An efficient finite element technique for modeling transport in fractured porous media, 1, Single species transport. Water Resour. Res., 19(3): 841-854.

Huyakorn, P.S., Lester, B.H. and Mercer, J.W., 1983b. An efficient finite element technique for modeling transport in fractured porous media, 2, Nuclide decay chain transport. Water Resour. Res., 19(5): 1286-1296.

Ippolito, I., Daccord, G., Hinch, E.J. and Hulin, J.P., 1994. Echo tracer dispersion in model fractures with a rectangular geometry. J. Contam. Hydrol., 16(1): 87-108.

Jackson, C.P., Hoch, A.R. and Todman, S., 2000. Self-consistency of a heterogeneous continuum porous medium representation of a fractured medium. Water Resour. Res. 36(1): 189-202.

Jourde, H., Cornaton, F., Pistre, S. and Bidaux, P., 2002. Flow behavior in a dual fracture network. J. Hydrol., 266: 99-119.

Jussel, P., Stauffer, F. and Dracos, T., 1994. Transport modeling in heterogeneous aquifers, 2, Three-dimensional transport model and stochastic numerical tracer experiments. Water Resour. Res., 30(6): 1819-1831.

Kischinhevsky, M. and Paes-Leme, P.J., 1997. Modelling and numerical simulations of contaminant transport in naturally fractured porous media. Transp. Porous Media, 26(1): 25-49.

Kitanidis, P.K., 1994. The concept of the dilution index. Water Resour. Res., 30(7): 20112026.

Lee, S. H., Lough, M. F. and Jensen C. L., 2001. Hierachical modeling of flow in naturally fractured formations with multiple length scales. Water Resour. Res. 37(3): 443-455. 
Leo, C.J. and Booker, J.R., 1996. A time-stepping finite element method for analysis of contaminant transport in fractured porous media. Int. J. Numer. Anal. Methods Geomech., 20(12): 847-864.

Lichtner, P. C. 2000. Critique of dual continuum formulations of multicomponent reactive transport in fractured porous media. In Dynamics of fluids in fractured rock, edited by B. Faybishenko, P. A. Witherspoon and S. M. Benson., American Geophysical Union, Washington, DC. 281-298.

Long, J.C.S., Remer, J.S., Wilson, C.R. and Witherspoon, P.A., 1982. Porous media equivalents for networks of discontinuous fractures. Water Resour. Res., 18(3): 645658.

McKay, L.D., Stafford, P.L. and Toran, L.E., 1997. EPM modeling of a field-scale tritium tracer experiment in fractured, weathered shale. Ground Water, 35(6): 997-1007.

Moreno, L. and Neretnieks, I., 1993. Fluid flow and solute transport in a network of channels. J. Contam. Hydrol., 14(3-4): 163-192.

Mourzenko, V.V., Yousefian, F., Kolbah, B., Thovert, J.F. and Adler, P.M., 2002. Solute transport at fracture intersections. Water Resour. Res. 38(1). doi: 10.1029/2000WR000211.

National Research Council, 1996. Rock Fractures and Fluid Flow: Contemporary Understanding and Applications. U.S. Committee on Fracture Characterization and Fluid Flow ed. National Academy Press, Washington, D.C.

Neuman, S.P., 1990. Universal scaling of hydraulic conductivities and dispersivities in geologic media. Water Resour. Res., 26(8): 1749-1758.

Nordqvist, A.W., Tsang, Y.W., Tsang, C.F., Dverstorp, B. and Andersson, J., 1992. A variable aperture fracture network model for flow and transport in fractured rocks. Water Resour. Res., 28(6): 1703-1713. 
Ohman, J., Niemi, A. and Tsang, C.-F., 2005. A regional-scale particle-tracking method for nonstationary fractured media. Water Resour. Res. 41. W03016, doi: 10.1029/2004WR003498.

Park, Y.J. and Lee, K.K., 1999. Analytical solutions for solute transfer characteristics at continuous fracture junctions. Water Resour. Res., 35(5): 1531-1537.

Park, Y.J. and Lee, K.K., 2001. Effects of junction transfer characteristics on transport in fracture networks. Water Resour. Res., 37(4): 909-923.

Parney, R. and Smith, L., 1995. Fluid velocity and path length in fractured media. Geophys. Res. Lett., 22(11): 1437-1440.

Pickens, J.F. and Grisak, G.E., 1981. Modeling of scale-dependent dispersion in hydrogeologic systems. Water Resour. Res., 17(6): 1701-1711.

Press, W.H., Flannery, B.P., Teukolsky, S.A. and Vetterling, W.T., 1993. Numerical recipes in C: the art of scientific computing (2nd edition). Cambridge University Press, New York.

Rasmuson, A., 1985. Analysis of hydrodynamic dispersion in discrete fracture networks using the method of moments. Water Resour. Res., 21(11): 1677-1683.

Reichenberger, V., Jakobs, H., Bastian, P. and Helmig, R., 2005, A mixed-dimensional finite volume method for two-phase flow in fractured porous media. Adv. Water Resour., in press.

Robinson, J.W. and Gale, J.E., 1990. A laboratory and numerical investigation of solute transport in discontinuous fracture systems. Ground Water, 28(1): 25-36.

Schulze-Makuch, D., 2005. Longitudinal dispersivity data and implications for scaling behavior. Ground Water 43(3): 443-456.

Schwartz, F.W. and Smith, L., 1988. A continuum approach for modeling mass transport in fractured media. Water Resour. Res., 24(8): 1360-1372. 
Schwartz, F.W., Smith, L. and Crowe, A.S., 1983. A stochastic analysis of macroscopic dispersion in fractured media. Water Resour. Res., 19(5): 1253-1265.

Smith, L. and Schwartz, F.W., 1984. An analysis of the influence of fracture geometry on mass transport in fractured media. Water Resour. Res., 20(9): 1241-1252.

Smith, L. and Schwartz, F.W., 1993. Solute transport through fracture networks. In Flow and Contaminant Transport in Fractured Rocks, edited by J. Bear, C. F. Tsang and G. de Marsily. Academic Press, San Diego, CA. 129-167.

Smith, P.A., Gautschi, A., Vomvoris, S., Zuidema, P. and Mazurek, M., 1997. The development of a safety assessment model of the geosphere for a repository sited in the crystalline basement of northern Switzerland. J. Contam. Hydrol., 26: 309-324.

Stafford, P., Toran, L. and McKay, L., 1998. Hydrology influence of fracture truncation on dispersion: A dual permeability model. J. Contam. Hydrol., 30(1-2): 79-100.

Sudicky, E.A. and Frind, E.O., 1982. Contaminant transport in fractured porous media: Analytical solutions for a system of parallel fractures. Water Resour. Res., 18(6): 1634-1642.

Tang, D.H., Frind, E.O. and Sudicky, E.A., 1981. Contaminant transport in fractured porous media: Analytical solution for a single fracture. Water Resour. Res., 17(3): 555-564.

Therrien, R. and Sudicky, E.A., 1996. Three-dimensional analysis of variably-saturated flow and solute transport in discretely fractured porous media. J. Contam. Hydrol., 23(1-2): $1-44$.

Tsang, C.F. and Neretnieks, I., 1998. Flow channeling in heterogeneous fractured rocks. Rev. Geophys., 36(2): 275-298.

Tsang, Y.W., Tsang, C.F., Hale, F.V. and Dverstorp, B., 1996. Tracer transport in a stochastic continuum model of fractured media. Water Resour. Res., 32(10): 3077-3092. 
Ubertosi, F., 2003. Résolution numérique de l'écoulement transitoire dans des réseaux de fractures 2D. [Numerical simulation of transient flow in 2D fracture networks]. Geosciences DEA report (in French). University of Poitiers, France.

Velde, B., Dubois, J., Moore, D. and Touchard, G., 1991. Fractal patterns of fractures in granites. Earth Planet. Sci. Lett., 104: 25-35.

Vignes-Adler, M., Lepage, A. and Adler, P.M., 1991. Fractal analysis of fracturing in two african regions, from satellite imagery to ground scale. Tectonophysics, 196(1-2): 6986.

Wels, C. and Smith, L., 1994. Retardation of sorbing solutes in fractured media. Water Resour. Res., 30(9): 2547-2563.

Wu, Y.-S., Liu, H.H. and Bodvarsson, G.S., 2004. A triple-continuum approach for modeling flow and transport processes in fractured rock. J. Contam. Hydrol. 73: 145-179.

Yamashita, R. and Kimura, H., 1990. Particle-Tracking technique for nuclide decay chain transport in fractured porous media. J. Nucl. Sci. Technol., 27(11): 1041-1049.

Yates, S.R., 1990. An analytical solution for one-dimensional transport in heterogeneous porous media. Water Resour. Res., 26(10): 2331-2338.

Yates, S.R., 1992. An analytical solution for one-dimensional transport in porous media with an exponential dispersion function. Water Resour. Res., 28(8): 2149-2154. 


\begin{tabular}{lc}
\hline \multicolumn{1}{c}{ Parameters } & Values \\
\hline Fracture length $L$ & $10 \mathrm{~m}$ \\
Flow velocity $u_{f}$ & $5 \times 10^{-5} \mathrm{~m} / \mathrm{s}$ \\
Molecular diffusion coefficient $D_{m}$ & $1 \times 10^{-9} \mathrm{~m}^{2} / \mathrm{s}$ \\
Constant $\varpi$ (linear dispersion model, test SF1) & 0.05 \\
Constant $\Phi$ (exponential dispersion model, test SF2) & 0.2 \\
Constant $\kappa$ (exponential dispersion model, test SF2) & 0.05 \\
\hline
\end{tabular}

Table 1. Input parameters in tests SF1 $\left(D_{f}=\varpi x u_{f}+D_{m}\right)$ and SF2 $\left(D_{f}=\Phi[1-\exp (-\kappa x)] u_{f}+\right.$ $D_{m}$ )

\begin{tabular}{lc}
\hline \multicolumn{1}{c}{ Parameters } & Values \\
\hline Dispersivity $\alpha$ in the fractures & $1 \mathrm{~m}$ \\
Molecular diffusion coefficient $D_{m}$ & $5 \times 10^{-9} \mathrm{~m}^{2} / \mathrm{s}$ \\
Matrix porosity $\theta_{m}$ & 0.05 \\
Effective diffusion coefficient $D_{e}$ & $10^{-13} \mathrm{~m}^{2} / \mathrm{s}$ \\
Bulk density of the rock matrix $\rho_{m}$ & $2200 \mathrm{~kg} / \mathrm{m}^{3}$ \\
Sorption coefficient on the fracture walls $k_{f}$ & $5 \times 10^{-6} \mathrm{~m}$ \\
Matrix sorption coefficient $k_{m}$ & $5 \times 10^{-7} \mathrm{~m}^{3} / \mathrm{kg}$ \\
\hline
\end{tabular}

Table 2. Transport parameters in test DFN1 (fracture network problem). 

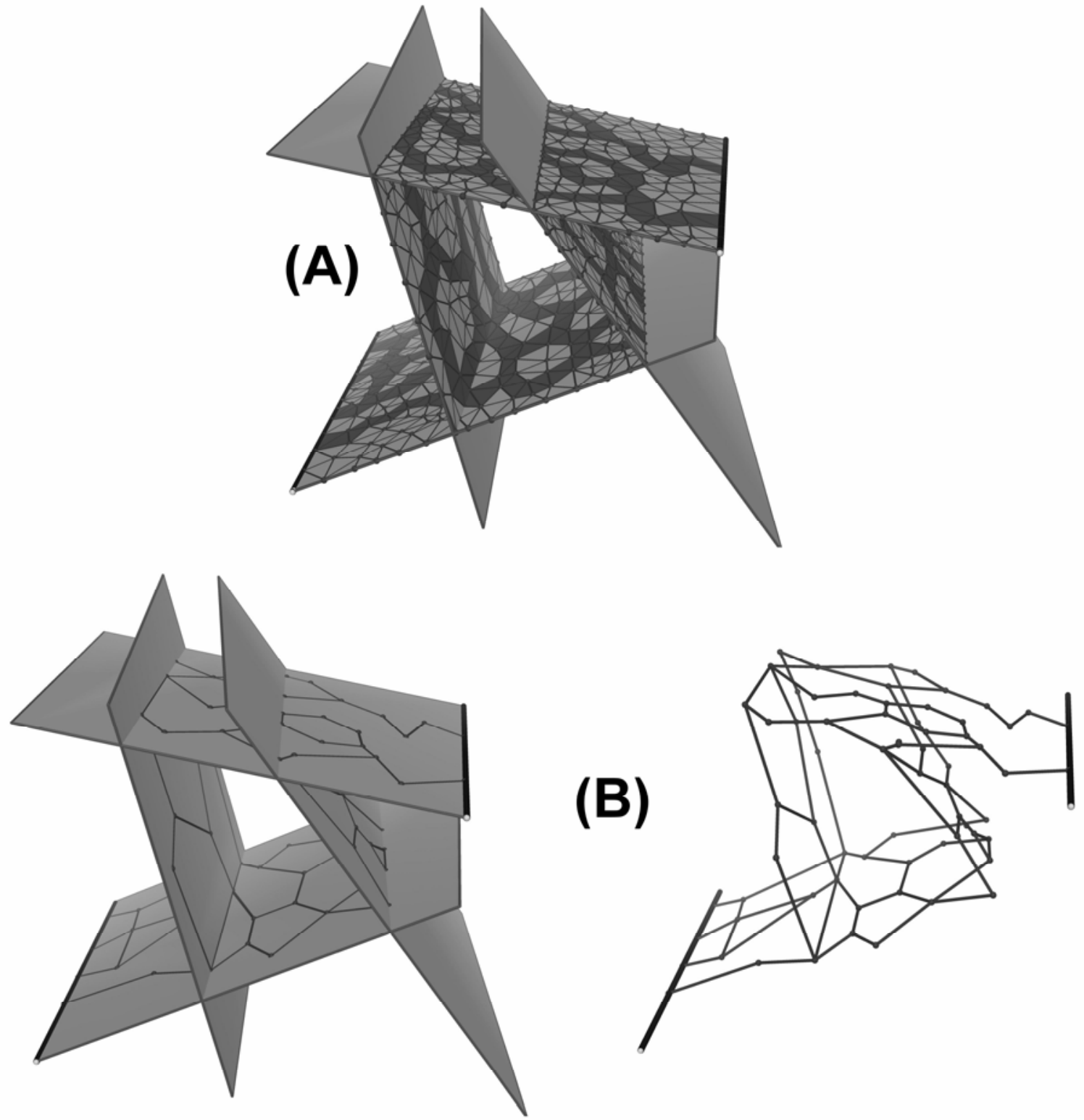

Fig. 1. Modelling approaches for 3D fracture networks. A: discretisation of fracture planes, the greyed cells correspond to those where most of the flow (and transport) takes place; B: generation of pipe networks in fracture planes. 


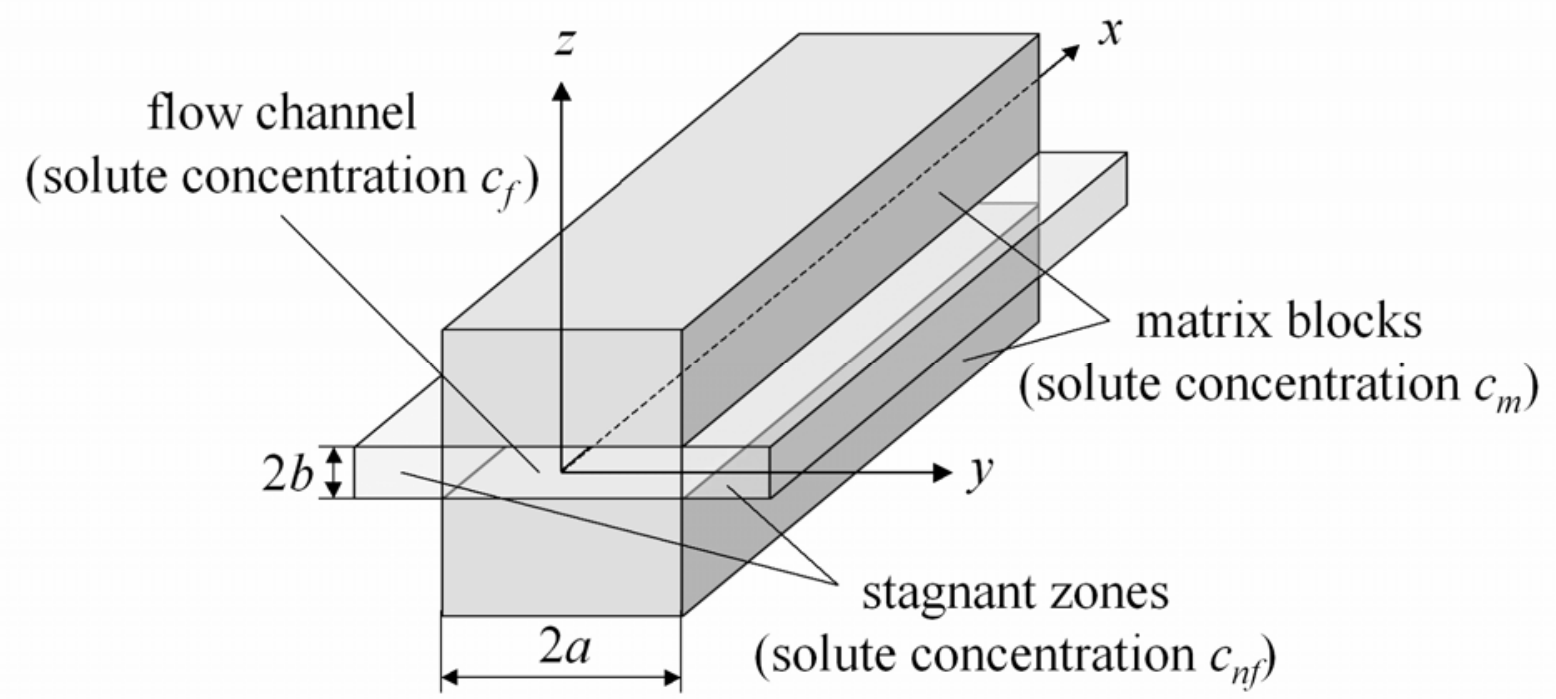

Fig. 2. Schematic illustration of a fracture-matrix system with both flowing and non-flowing pore spaces in the fracture plane.

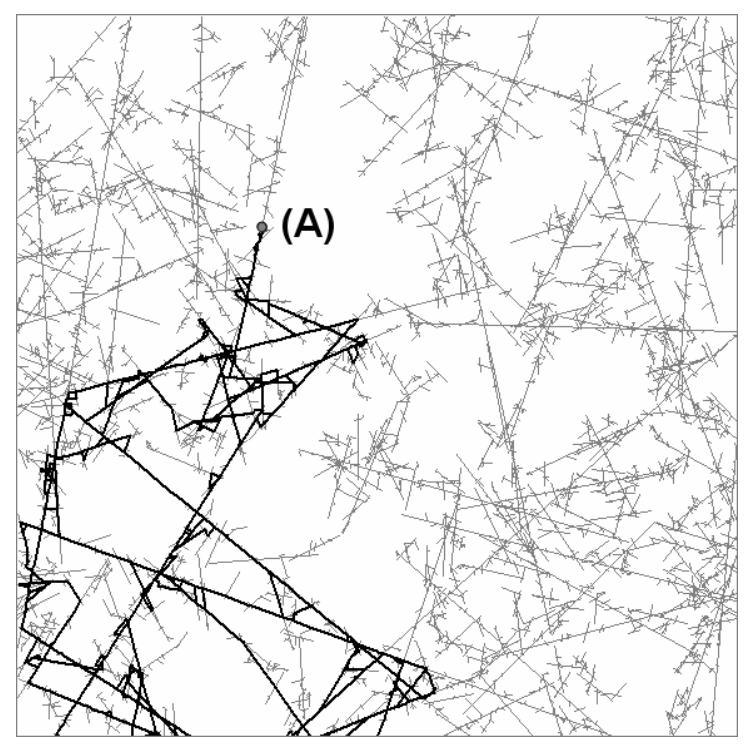

Fig. 3. Identification of elementary paths in the SOLFRAC program for an injection in (A). 


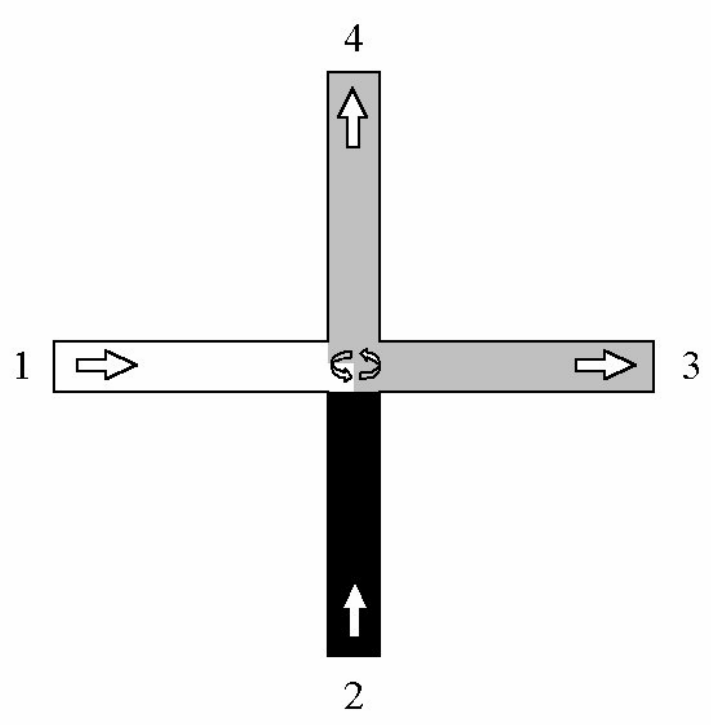

(a)

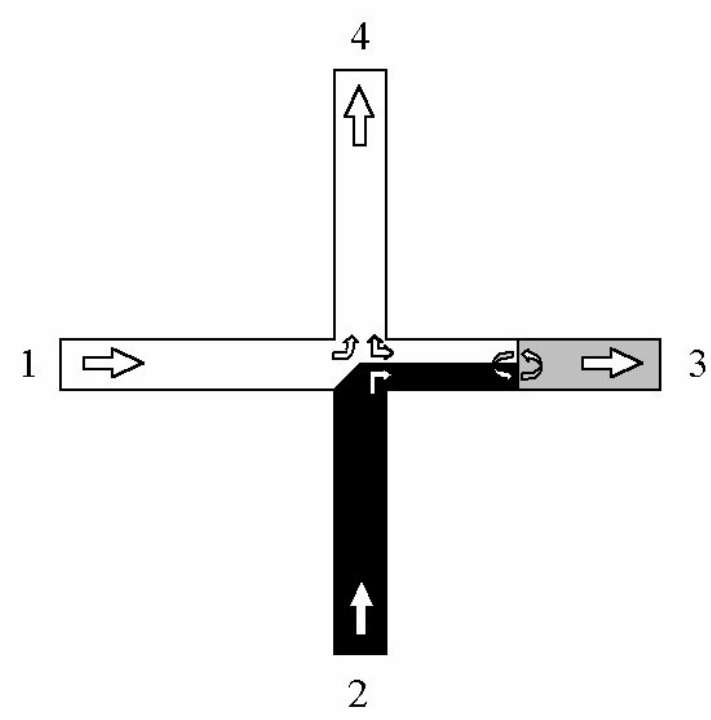

(b)

Fig. 4. Solute mass partitioning at a "continuous" fracture junction: (a) "perfect mixing model", (b) "streamtube model" ; reprinted from Water Resources Research 35(5), Park Y-J, Lee K-K, Analytical solutions for solute transfer characteristics at continuous fracture junctions, pp1531-1537, Copyright (1999), with permission from American Geophysical Union. Note that the streamtube model may lead to a heterogeneous distribution of concentrations across the section of an outlet bond, but it is assumed that the transverse molecular diffusion results in a fast homogenisation in the bond. 


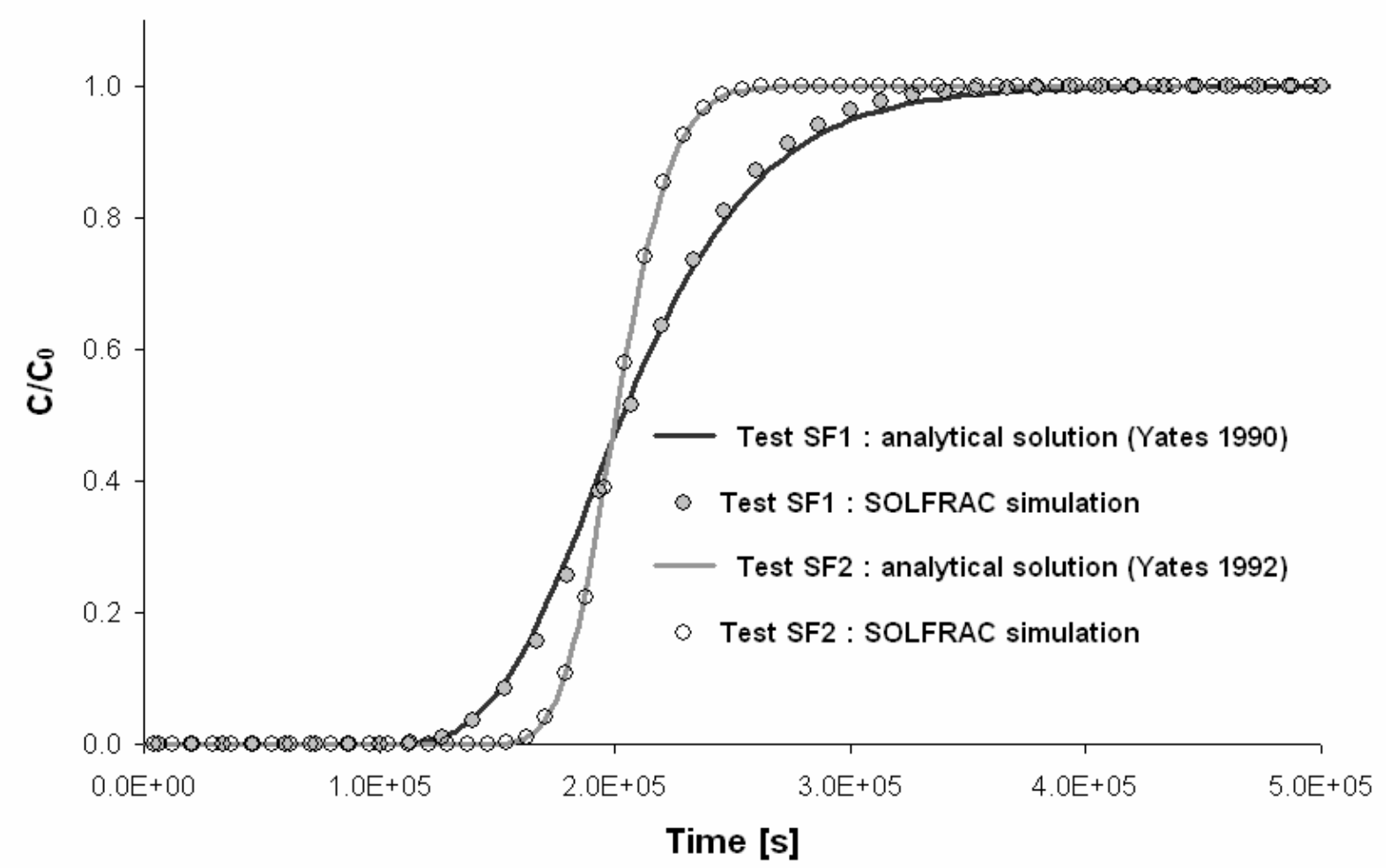

Fig. 5. Solute transport in a single fracture with scale-dependent dispersion: comparison between SOLFRAC simulations and analytical solutions. Test SF1: linear dispersion $\left(D_{f}=\right.$ $\left.\varpi x u_{f}+D_{m}\right)$; Test SF2: exponential dispersion $\left(D_{f}=\Phi[1-\exp (-\kappa x)] u_{f}+D_{m}\right)$. 


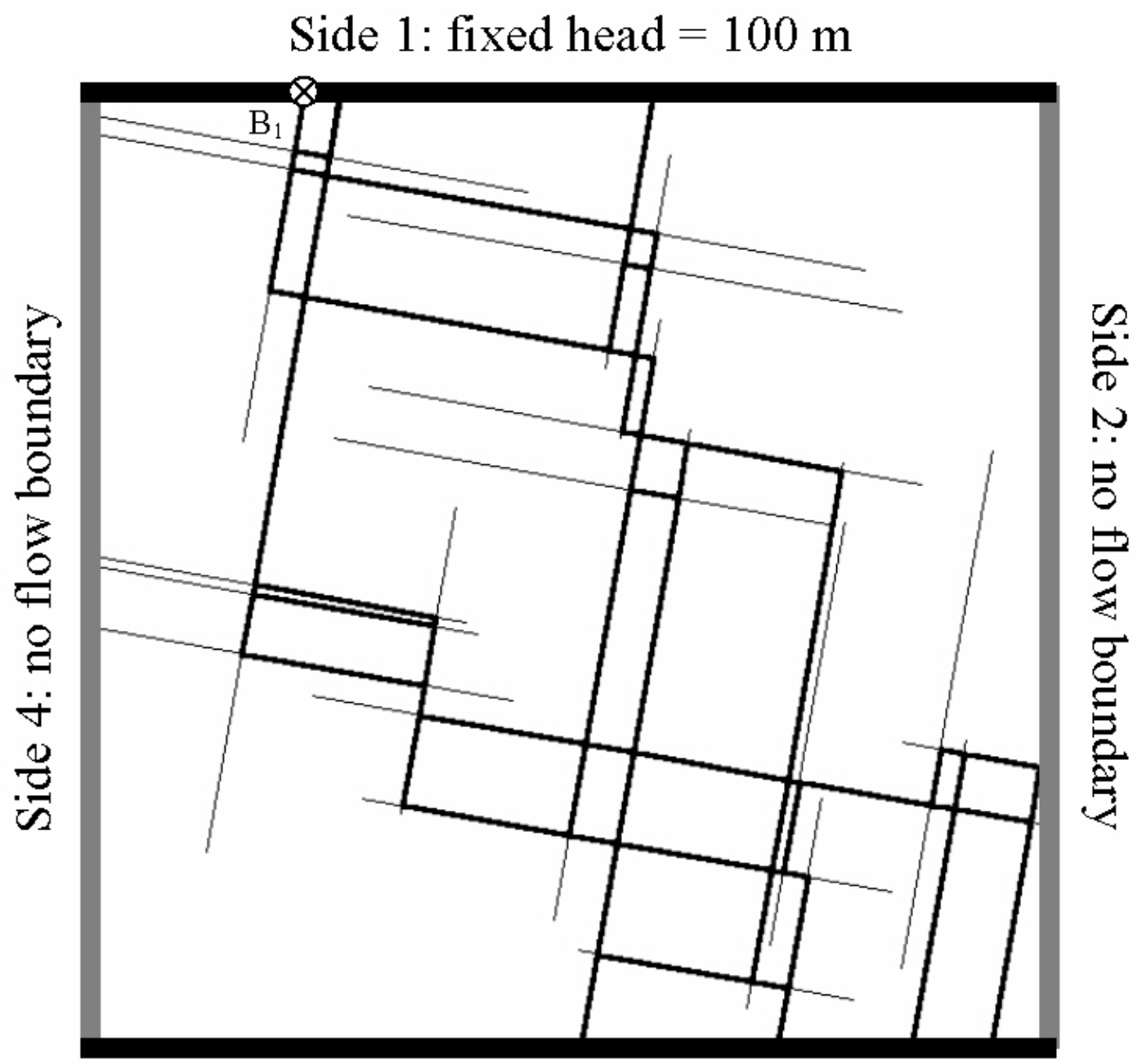

Side 3: fixed head $=99 \mathrm{~m}$

Fig. 6. The fracture network of test DFN1: size $=350 \times 350 \mathrm{~m} ; 27$ fractures. The 71 bold lines show the flowing bonds, i.e. the backbone of the network. The tracer particles were injected at the inlet of bond B1. 


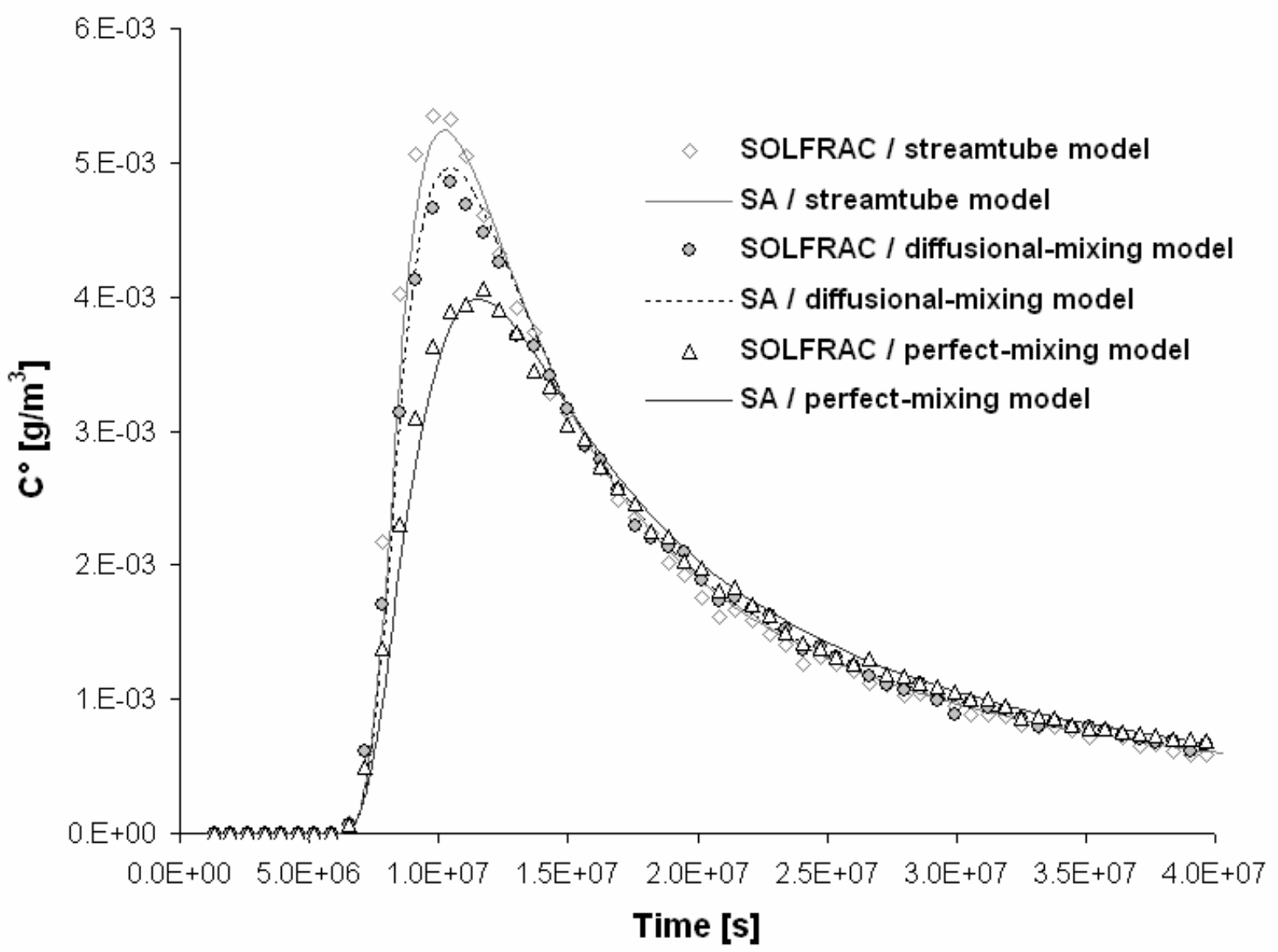

Fig. 7. Test DFN1: comparison between SOLFRAC simulations and semi-analytical (SA) computed breakthrough curves. 